\title{
Investigating the Sources of Default Risk: Lessons from Empirically Evaluating Credit Risk Models
}

\author{
Gurdip Bakshi, Dilip Madan, Frank Zhang*
}

February 28, 2001

\footnotetext{
*Bakshi and Madan are both at Department of Finance, Robert H. Smith School of Business, University of Maryland, College Park, MD 20742, and Zhang is at Federal Reserve Board, Division of Research and Statistics, Mail Stop 91, Washington D.C. 20551. Bakshi can be reached at Tel: 301-405-2261, Email: gbakshi@rhsmith.umd.edu, Website: www.rhsmith.umd.edu/finance/gbakshi/; Madan at Tel: 301-405-2127, Email: dbm@rhsmith.umd.edu, and Website: www.rhsmith.umd.edu/finance/dmadan/; and Zhang at Tel: 202-452-3760, Email: xzhang@frb.gov. We thank Roger Betancourt, Elton Daal, Michael Fu, Mark Grinblatt, Levent Guntay, Nengjiu Ju, Chuck LaHaie, Biao Lu, Yuki Naka, Lemma Senbet, Ken Singleton, Haluk Unal, and Gerald Whitney for helpful discussions. An earlier version of this paper was presented at Fannie Mae, Federal Reserve Board, Georgia Institute of Technology, University of New Orleans, and SUNY Binghamton. Conference participants at the 2001 AFA meetings in New Orleans and the Accounting and Finance Conference at Michigan provided several useful comments. The suggestions of Greg Duffee and Tyler Shumway have improved this paper. The views expressed herein are the authors own and do not necessarily reflect those of the Federal Reserve Board or its staff.
} 


\title{
Investigating the Sources of Default Risk: \\ Lessons from Empirically Evaluating Credit Risk Models
}

\begin{abstract}
From a credit risk perspective, little is known about the distress factors - economy-wide or firm-specific - that are important in explaining variations in defaultable coupon yields. This paper proposes and empirically tests a family of credit risk models. Empirically, we find that firm-specific distress factors play a role (beyond treasuries) in explaining defaultable coupon bond yields. Credit risk models that take into consideration leverage and book-to-market are found to reduce out-of-sample yield fitting errors (for the majority of firms). Moreover, the empirical evidence suggests that interest rate risk may be of first-order prominence for pricing and hedging. Measured by both out-of-sample pricing and hedging errors, the credit risk models perform relatively better for high grade bonds. Controlling for credit rating, the model performance is generally superior for longer maturity bonds compared to its shorter maturity counterparts. Using equity as an instrument reduces hedging errors. This paper provides an empirical investigation of credit risk models using observable economic factors.
\end{abstract}


Building credit risk models as the basis for evaluating default exposures is of fundamental importance to financial economists. Consistent with this objective, theoretical research continues to shed light on the qualitative nature of credit spreads and their dependencies on essential features of the defaultable contract (i.e., credit rating of the participating parties and firm-specific/systematic default characteristics). For instance, Jarrow and Turnbull (1995) propose a valuation framework where the underlying asset or the derivative counterparty may default. Duffie and Singleton (1997, 1999 ) treat default as an unpredictable event governed by the instantaneous probability of default. On the other hand, Madan and Unal (1998) analytically decompose the risk of default into components related to timing and recovery risks. Each of the aforementioned approaches view default as occurring at a surprise stopping time. In a related work, Jarrow, Lando, and Turnbull (1997) develop a theoretical model where the bankruptcy process obeys a discrete state space Markov chain in credit rating (see also the generalization in Lando (1998)). Finally, in Merton (1974), Longstaff and Schwartz (1995) and Collin-Dufresne and Goldstein (1999), default is modeled using a predictable stopping time; namely, default occurs when a continuous process like the firm value reaches a default boundary. Each contribution provides a rich parameterization of the price of credit sensitive securities.

While significant advances have been made in interpreting credit risks, there is a relative paucity of empirical studies that investigate the sources of credit risks using observable economic factors (the exceptions will be noted shortly): Which fundamental economic factors - economywide or firm-specific - capture variations in default risk? Which credit risk model is suitable for pricing and marking-to-market default contingent securities? Which model performs the best in hedging credit exposures (in all relevant dimensions)? Empirical investigations of credit risk models attempting to analytically capture patterns of structural dependencies on theoretically interpretable grounds are clearly desirable from several perspectives (for example in implementing the Basle committee recommendations on managing default risk).

Even when a particular set of models is theoretically appealing and reasonable on normative grounds, the selection of the preferred credit risk model has been hampered by a few considerations. First, there is often a mismatch between theoretical constructs and traded securities: the majority of the traded debt instruments are coupon paying, while extant models focus attention on valuing defaultable zeros. When default is a factor, the coupon bonds are not a portfolio of zeros (all remaining coupons share the same default time). Second, although conceptually elegant, the models in the predictable stopping time class are difficult to implement. As argued elsewhere, the capital structure of the firm is generally far too complex to specify recovery (to all claimants) in the event of default. Moreover, at the empirical level, these models generate a counterfactually low short-term yield spread for high quality borrowers (see the relevant discussion in Briys and 
de Verenne (1997), Collins-Dufresne and Goldstein (1999), Duffee (1999), Duffie and Singleton (1999), and Shumway (2001)).

The class of models we test empirically share a number of features in common. One, our characterization of credit risk relies on the surprise stopping time approach. In particular, we develop a class of credit risk models that incorporate the Duffie-Singleton (1999) assumption that recovery (in default) is proportional to the pre-defaultable market value of debt. Two, it is shown that the price of the defaultable coupon bond can be interpreted as the martingale expectation of the promised face value and coupons, when each payoff is discounted by the relevant defaultable discount rate; this rate embodies time value, loss arrival rates and recovery. Three, we develop in analytical closed-form, a set of three-factor credit risk models that depend on systematic as well as firm-specific distress variables. To be consistent with the existing literature, we posit two factors - the risk-free interest rate and its stochastic long-run mean - to capture macroeconomic effects on the instantaneous likelihood of default (Duffee (1998) and Litterman and Scheinkman (1991)). The firm-specific distress factors we consider include leverage, book-to-market, profitability, lagged credit spread, and scaled equity price. The sources of default risk are apparent in our empirical framework.

Our empirical study that examines the pricing and hedging accuracy of credit risk models with observable economic factors (six distinct models) is based on a panel of 93 corporations and treasury STRIPS. This data set is merged from Lehman Brothers Fixed Income Database, COMPUSTAT and CRSP. From the original data, we omitted bonds that are putable, callable, convertible, or have a sinking fund provision. Overall, the filtered database consists of more than 46,000 corporate coupon bond prices and 20,000 treasury STRIPS.

A two-step procedure is followed to implement every credit risk model, and to infer the structural parameters. In the first step, we estimate the risk-neutralized parameters of the term structure using only treasury STRIPS. Keeping the treasury parameters constant across all firms, we estimate the risk-neutralized parameters of the firm-specific distress factor. We employed a twostep procedure because the joint estimation is computationally infeasible. Our empirical exercises support the following general findings:

- Firm specific distress factors such as leverage and book-to-market are positively related to yields in the firm cross-section. The relationship remains significant, even after controlling for credit rating;

- Incorporating a stochastic mean interest rate factor to the credit risk model enhances its performance. Our analysis indicates that the sensitivity of the defaultable discount rate to the interest rate is positive but less than unity. Consistent with our predictions, the 
estimated unconditional credit yield is higher for less credit worthy firms;

- Measured by both the absolute percentage pricing errors and the absolute yield basis point errors, the leverage ratio model and the book-to-market ratio model consistently outperform the interest rate only model (the credit risk model with no firm-specific distress). Leverage and book-to-market considerations are relevant for about $70 \%$ of the firms. The model improvement is most pronounced among long-term bonds;

- For our bond sample, interest rate risk captures the first-order effect of default. Once interest rate considerations are taken into account, the pricing improvement is marginal. This result is robust across subsamples restricted by credit rating, maturity and industries;

- The credit risk models exhibit distinct average mispricing patterns: the leverage and bookto-market ratio models overprice, while the interest rate model underprice, long-term bonds. The econometric analysis of valuation errors shows that if one were to consider expanding on the systematic default factors, the default premium would be a good candidate;

- Our pricing error metrics establish that credit risk models perform better for high grade bonds than for low grade ones; likewise, the empirical performance is superior for longer maturity bonds. Overall, our investigation supports the view that the credit risk models have pricing performance adequate for marking risk exposures.

We also evaluate the errors from delta-hedging a short position in the defaultable coupon bond. In this hedging strategy, we construct a replicating portfolio that consists of a positioning in two zero-coupon bonds and the underlying firm's equity. This research establishes several key insights. First, using equity as a hedging instrument reduces dynamic hedging errors. Second, the hedging effectiveness of the stock price model is superior relative to alternative credit risk models (based on absolute and mean percentage hedging errors). Third, the analysis reveals that interest rate risk is crucial to the profit/loss accounts of the hedger. All credit risk models over-hedge the target.

This paper is organized as follows. In Section 1, we present a generic framework to price defaultable coupon bonds. Section 2 proposes a class of three-factor credit risk models. The defaultable coupon bond data is described in Section 3. In Section 4, we examine the cross-sectional relationship between market yields and firm-specific distress factors. Section 5 describes the estimation procedure and the in-sample results. The out-of-sample pricing exercises are conducted in Section 6 . Section 7 outlines the hedging strategy and examines the hedging performance of credit risk models. Conclusions are provided in Section 8. All technical details are in the Appendix. 


\section{Pricing Defaultable Coupon Bonds}

Defaultable coupon bonds, like other debt contracts, are defined by their promised stream of cash flows through time. Typically these consist of a promised face value, F, to be paid at maturity $\mathrm{T}$, and a stream of coupon payments to be paid in the interim. To accommodate both discrete and continuous coupon payments, we denote by $\mathrm{C}(\mathrm{t})$ the non-decreasing function of cumulated coupon payments until time $t$. In all generality, the function $\mathrm{C}(\mathrm{t})$ need not be deterministic and could depend on economic information as it becomes available.

In addition to specifying the promised payments, defaultable debt recognizes that there is a random time $\mathcal{T}$ at which default occurs. At this time, a payment $y(\mathcal{T})$ is made in fulfillment of the debt obligation. The recovery, $y(\mathcal{T})$, if any, is generally far below the value of the remaining promised payments. We associate with the random time $\mathcal{T}$, the unit step function $\chi(t)$, as made exact below:

$$
\chi(t)= \begin{cases}1 & t \geq \mathcal{T} \\ 0 & \text { Otherwise. }\end{cases}
$$

The defaultable debt contract can now be defined by the entities: $(\mathrm{F}, \mathrm{T}, \mathrm{C}(\mathrm{t}), \chi(t), \mathrm{y}(\mathrm{t}))$ that are presumed adapted to the information filtration $\Im_{t}, 0 \leq t \leq T$ of a probability space $(\Omega, \Im, P)$, satisfying the usual technical conditions.

We suppose that the spot interest rate is given by $\mathrm{r}(\mathrm{t})$ and $b(t) \equiv \exp \left(\int_{0}^{t} r(s) d s\right)$ is the associated accumulation of the money market account. According to Duffie (1996), the absence of arbitrage opportunities is ensured by the existence of a probability measure $\mathrm{Q}$ equivalent to $\mathrm{P}$ under which the money market discounted gains processes for all assets are martingales. It follows that the time $t$ price of the defaultable coupon bond with maturity $\tau$ periods from time $t$, denoted $P(t, \tau)$, is given by:

$$
\begin{aligned}
P(t, \tau)= & E_{t}^{Q}\left\{\int_{t}^{t+\tau} \frac{b(t)}{b(u)}(1-\chi(u)) d C(u)+\frac{b(t)}{b(t+\tau)}(1-\chi(t+\tau)) F\right. \\
& \left.+\int_{t}^{t+\tau} \frac{b(t)}{b(u)}(1-\chi(u)) y(u) d \chi(u) \mid \Im_{t}\right\}
\end{aligned}
$$

where $E_{t}^{Q}$ is the expectation operator under the probability measure $Q$.

The first integral in equation (2) accounts for the stream of coupon payments received as long as there is no default and stopped at the default time. The second term accounts for the receipt of the promised face value given no default. Finally, the last integral accounts for the single recovery at the default time (on noting that $d \chi(u)$ equals the Kronecker delta function at $u=\tau$, and is 
zero at times other than the default time when it is one). As articulated in Duffie and Singleton (1997, 1999) and Madan and Unal (1998), the difficulty in evaluating equation (2) comes from having to address the discontinuous random step process $\chi(t)$.

Most default models employ a stopping time to characterize default time. Specifically in the class of models that use predictable stopping time, default occurs when a continuous process like the firm value reaches a default boundary (i.e., Merton (1974), Longstaff and Schwartz (1995) and Collin-Dufresne and Goldstein (1999)). The second class of models view default as occurring at a surprise stopping time (Duffie and Singleton (1997, 1999), Jarrow and Turnbull (1995), and Madan and Unal (1998)). These models, though silent on the definition of the default event, focus their attention on the instantaneous likelihood of default. Our formulation of default in (2) is consistent with the surprise stopping time approach.

For a surprise default time that is a stopping time, there exists a positive process $h(t)$, called the hazard rate process, such that

$$
\chi(t)-\int_{0}^{t}(1-\chi(u)) h(u) d u
$$

is a martingale. When we have a martingale under the probability $Q$, then we refer to $h(t)$ as the risk-neutral hazard rate process. Heuristically speaking, $h(t) d t$ models the probability of default in the interval $(t, t+d t)$, the instantaneous likelihood of default. The process $h(t)$ is adapted to a subfiltration of continuous evolving information $\mathcal{G}_{t}$. In this case, Madan and Unal (1998) show that:

$$
E_{t}^{Q}\left[(1-\chi(u)) \mid \mathcal{G}_{u}\right]=\exp \left(-\int_{t}^{u} h(s) d s\right) .
$$

Using (4) and iterated expectations, it immediately follows that

$$
\begin{aligned}
P(t, \tau)= & E_{t}^{Q}\left\{\int_{t}^{t+\tau} \frac{b(t)}{b(u)} \exp \left(-\int_{t}^{u} h(s) d s\right) d C(u)+\frac{b(t)}{b(t+\tau)} \exp \left(-\int_{t}^{t+\tau} h(s) d s\right) F\right. \\
& \left.+\int_{t}^{t+\tau} \frac{b(t)}{b(u)} \exp \left(-\int_{t}^{u} h(s) d s\right) y(u) h(u) d u \mid \mathcal{G}_{t}\right\} .
\end{aligned}
$$

Unlike equation (2), the pricing equation (5) eliminates all reference to the discontinuous process $\chi(t)$. Equation (5) reduces the problem of pricing defaultable coupon debt to that of pricing non-defaultable debt with an altered discount rate and cash flow claim.

If we now follow Duffie and Singleton (1999) and define recovery as a proportion, $\lambda(t)$, of the pre-default value of the defaultable debt so that

$$
y(t)=\lambda(t) P\left(t_{-}, \tau\right),
$$


then an application of Ito's lemma shows that the price of the defaultable debt may be written as (see the Appendix for intermediate steps):

$$
\begin{aligned}
P(t, \tau)= & E_{t}^{Q}\left\{\int_{t}^{t+\tau} \exp \left(-\int_{t}^{t+u}[r(s)+h(s)(1-\lambda(s))] d s\right) d C(u)+\right. \\
& \left.F \exp \left(-\int_{t}^{t+\tau}[r(s)+h(s)(1-\lambda(s))] d s\right) \mid \mathcal{G}_{t}\right\}
\end{aligned}
$$

Because it is not generally possible (in the Duffie-Singleton approach) to separate the effects of hazard rate process $h(t)$ from that of the loss process $(1-\lambda(t))$, define the aggregate defaultable discount rate as:

$$
R(t) \equiv r(t)+h(t)[1-\lambda(t)]
$$

This discount rate consolidates time value, loss arrival rates and recovery considerations. Then, in the case of deterministic and continuous coupon rate $c(t)$, the defaultable debt equation can be simplified as:

$$
P(t, \tau)=\int_{0}^{\tau} c(t+u) P^{*}(t, u) d u+F P^{*}(t, \tau)
$$

where

$$
P^{*}(t, u)=E_{t}^{Q}\left\{\exp \left(-\int_{t}^{t+u} R(s) d s\right) \mid \mathcal{G}_{t}\right\}
$$

is the price of the unit face defaultable zero-coupon bond with maturity $t+u$.

In the next section, we derive models for $R(t)$ that lead to empirically testable closed-form models for the price of defaultable coupon debt. In each credit risk model, the price of defaultable discount bonds is exponential affine in the state of the economy.

\section{A Class of Credit Risk Models}

Consider the family of aggregate defaultable discount rate models shown below (each firm is indexed by $n$ ):

$$
R_{n}(t)=\Lambda_{0, n}+\Lambda_{r, n} r(t)+\Lambda_{x, n} X_{n}(t), \quad n=1, \cdots, N,
$$

where $\mathrm{r}(\mathrm{t})$ is the spot interest rate and $X_{n}(t)$ surrogates firm-specific distress. This specification is theoretically reasonable, as it incorporates both an economy-wide variable and a firm-specific variable. To keep a parsimonious factor structure, we have assumed that distress is driven by a single-factor $X_{n}(t)$ and a single systematic risk factor $\mathrm{r}(\mathrm{t})$. Our characterization of $R_{n}(t)$ is sufficiently versatile to accommodate a K-factor model of $X_{n}(t)$, however. Like its default-free 
predecessor, the linearity of $\mathrm{R}(\mathrm{t})$ in $\mathrm{r}(\mathrm{t})$ and $\mathrm{X}(\mathrm{t})$ is employed for analytical tractability. Equation (11) forms a convenient basis for the empirical analysis of credit risk models.

Although not yet derived in closed-form, the coefficients $\Lambda_{0}, \Lambda_{r}$ and $\Lambda_{x}$ are key to understanding variations in defaultable yields. $\Lambda_{0}$ measures the level of the unconditional instantaneous credit yield. If $\Lambda_{r}$ is positive, defaultable bond yields are positively related to interest rates. Given the existing evidence on co-movements between treasury and corporate yield curves (Duffee (1998)), it is expected that $\Lambda_{r}$ is positive. Similarly, $\Lambda_{x}$ assesses the significance of the particular firm-specific distress variable. Assuming that $\mathrm{X}(\mathrm{t})$ is positively associated with firm-specific distress, the credit quality of the firm deteriorates when distress rises (provided $\Lambda_{x, n}>0$ ).

Three special cases of (11) are of relevance to the literature. CASE 1: Setting $\Lambda_{0}=\Lambda_{x}=0$ and $\Lambda_{r}=1$ gives the term structure of default-free bonds. CASE 2: Under the parametric restriction $\Lambda_{x, n}=0$, one obtains the class of credit risk models considered by Duffie and Singleton (1997). When $X(t)$ is a hidden Markov variable, our framework admits the specification adopted in Duffee (1999). CASE 3: The restriction $\Lambda_{r}=\Lambda_{x}=0$ reduces to the model of Jarrow and Turnbull (1995). Equation (11) indicates that cross-sectional variations in credit risk are primarily due to cross-sectional variations in $\Lambda_{0, n}, \Lambda_{r, n}, \Lambda_{x, n}$, and $X_{n}$ (the interest rate is common to all firms). A later analysis shows that the parameters of the defaultable discount rate vary systematically with credit rating, as modeled also by Jarrow, Lando, and Turnbull (1997). To be specific, the magnitude of the unconditional instantaneous credit yield, $\Lambda_{0, n}$, is lower for higher quality firms relative to its more distressed counterparts.

To obtain a class of tractable credit risk models, two modeling decisions are made for the remainder of the paper. We first specify the dynamics of the nominal interest rate and the firm-specific distress factor. Next, we justify our choice for the distress factors. At the outset, assume that the interest rate, $r(t)$, evolves according to a two-factor model (under the equivalent martingale measure):

$$
\begin{aligned}
& d r(t)=\kappa_{r}[z(t)-r(t)] d t+\sigma_{r} d \omega_{r}(t), \\
& d z(t)=\kappa_{z}\left[\mu_{z}-z(t)\right] d t+\sigma_{z} d \omega_{z}(t),
\end{aligned}
$$

where the long-run mean of the short rate is represented by $z(t) . \omega_{r}(t)$ and $\omega_{z}(t)$ are standard Brownian motions, with correlation $\rho_{r, z}$. As is conventionally interpreted, $\kappa_{r}\left(\kappa_{z}\right)$ are the rates of mean-reversion for $r(t)(z(t))$. The diffusion coefficients $\sigma_{r}$ and $\sigma_{z}$ are constants. $z(\mathrm{t})$ is unobservable and will be inferred from the treasury yield curve.

Under the stated assumptions (12)-(13), the price of default-free discount bond maturing in $\tau$ 
periods from time t, $B(t, \tau)$, is:

$$
B(t, \tau) \equiv E_{t}^{Q}\left\{\exp \left(-\int_{t}^{t+\tau} r(s) d s\right)\right\}=\exp [-\bar{\alpha}(\tau)-\bar{\beta}(\tau) r(t)-\bar{\gamma}(\tau) z(t)]
$$

where $\bar{\beta}(\tau) \equiv \frac{1-\exp \left(-k_{r} \tau\right)}{k_{r}}, \bar{\gamma}(\tau) \equiv \frac{1-\exp \left(-\kappa_{z} \tau\right)}{\kappa_{z}}+\frac{\exp \left(-\kappa_{z} \tau\right)-\exp \left(-\kappa_{r} \tau\right)}{\kappa_{z}-\kappa_{r}}$ and $\bar{\alpha}(\tau) \equiv-\frac{1}{2} \sigma_{r}^{2} \int_{0}^{\tau} \bar{\beta}^{2}(s) d s-$ $\frac{1}{2} \sigma_{z}^{2} \int_{0}^{\tau} \bar{\gamma}^{2}(s) d s+\kappa_{z} \mu_{z} \int_{0}^{\tau} \bar{\gamma}(s) d s-\rho_{r, z} \sigma_{r} \sigma_{z} \int_{0}^{\tau} \bar{\beta}(s) \bar{\gamma}(s) d s$. The two-factor model is adopted for several reasons. First, when fitted to the treasury yield curve, it is found to reduce the empirical fitting errors relative to the one-factor counterpart (see also, among others, Buhler, Uhrig, Walter, and Webber (1999) and Dai and Singleton (2000)). Statistically, the one-factor model is rejected in favor of a two-factor model of interest rates. Second, Litterman and Scheinkman (1991), Chen and Scott (1993) and Duffee (1998) have shown that movements in the level and slope of the yield curve capture a large fraction of treasury term structure variations. These considerations suggest that a two-factor model is desirable on empirical and theoretical grounds. Finally, though more complex interest rate models could be employed, this comes at the cost of a loss of parsimony and implementability.

Next, for its analytical tractability, we assume that the underlying distress factor obeys a process of the type:

$$
d X_{n}(t)=\kappa_{x, n}\left[\mu_{x, n}-X_{n}(t)\right] d t+\sigma_{x, n} d \omega_{x, n}(t)
$$

where $\omega_{x}$ is a standard Brownian motion. Let $\rho_{r, x} \equiv \operatorname{Cov}_{t}\left(\omega_{r}, \omega_{x}\right)$. For each $X_{n}(t)$ proxy, assumptions (12)-(13) and (15) lead to a distinct model of credit risk. Since the structural parameters have a standard interpretation, unnecessary repetition is avoided. Notice that the form of (15) is a robust three parameter specification for the process of the firm-specific distress factor.

Consider now the price of a unit face defaultable discount bond with $\tau$ periods left to maturity. Using the dynamics of $r$ and $X$ and solving (10), we have (the subscript $n$ is suppressed):

$$
P^{*}(t, \tau)=\exp [-\alpha(\tau)-\beta(\tau) r(t)-\gamma(\tau) z(t)-\theta(\tau) X(t)]
$$

where:

$$
\begin{aligned}
\beta(\tau) & \equiv \frac{\Lambda_{r}\left[1-\exp \left(-k_{r} \tau\right)\right]}{k_{r}}, \\
\gamma(\tau) & \equiv \frac{\Lambda_{r}\left[1-\exp \left(-\kappa_{z} \tau\right)\right]}{\kappa_{z}}+\frac{\Lambda_{r}\left[\exp \left(-\kappa_{z} \tau\right)-\exp \left(-\kappa_{r} \tau\right)\right]}{\left(\kappa_{z}-\kappa_{r}\right)}, \\
\theta(\tau) & \equiv \frac{\Lambda_{x}\left[1-\exp \left(-\kappa_{x} \tau\right)\right]}{\kappa_{x}}
\end{aligned}
$$


and

$$
\begin{aligned}
\alpha(\tau) \equiv & \Lambda_{0} \tau-\frac{1}{2} \sigma_{r}^{2} \int_{0}^{\tau} \beta^{2}(s) d s+\kappa_{x} \mu_{x} \int_{0}^{\tau} \theta(s) d s-\frac{1}{2} \sigma_{z}^{2} \int_{0}^{\tau} \gamma^{2}(s) d s-\frac{1}{2} \sigma_{x}^{2} \int_{0}^{\tau} \theta^{2}(s) d s \\
& +\kappa_{z} \mu_{z} \int_{0}^{\tau} \gamma(s) d s-\rho_{r, x} \sigma_{r} \sigma_{x} \int_{0}^{\tau} \beta(s) \theta(s) d s-\rho_{r, z} \sigma_{r} \sigma_{z} \int_{0}^{\tau} \beta(s) \gamma(s) d s .
\end{aligned}
$$

We first observe that the price of the defaultable zero is exponential affine in three state variables: the interest rate, the stochastic long-run mean interest rate and the firm-specific distress factor. The model has 13 structural parameters. Specifically, there are 3 parameters in the defaultable discount rate specification, 6 in the interest rate process and 4 associated with the dynamics of the firm-specific distress factor.

Second, under positivity of $\Lambda_{r}$ and the speed of adjustments in the interest rate process, the defaultable discount bond price is negatively related to $r(t)$ and $z(t)$. More precisely, we have

$$
\begin{aligned}
& \Delta_{r}^{*}(t, \tau) \equiv \frac{\partial P^{*}(t, \tau)}{\partial r}=-\beta(\tau) P^{*}(t, \tau)<0, \\
& \Delta_{z}^{*}(t, \tau) \equiv \frac{\partial P^{*}(t, \tau)}{\partial z}=-\gamma(\tau) P^{*}(t, \tau)<0 .
\end{aligned}
$$

Furthermore, the bond price is also negatively associated with the distress factor, as seen by

$$
\Delta_{x}^{*}(t, \tau) \equiv \frac{\partial P^{*}(t, \tau)}{\partial X}=-\theta(\tau) P^{*}(t, \tau)<0,
$$

provided $\Lambda_{x}>0$. These expressions for the local risk exposures are later employed to develop delta-neutral hedges for marked-to-market risks.

Third, the yield to maturity of the defaultable discount bond, for maturity $\tau$, is

$$
Y^{*}(t, \tau) \equiv-\frac{\log \left[P^{*}(t, \tau)\right]}{\tau}=\frac{\alpha(\tau)+\beta(\tau) r(t)+\gamma(\tau) z(t)+\theta(\tau) X(t)}{\tau}
$$

From expressions (17)-(19), we can see that the sensitivity of yield to maturity with respect to each of the three state variables is decreasing in maturity. Based on this feature of the model, the risk exposures of long-term defaultable discount bonds are lower and it may be possible to ignore these risks in developing hedges. Albeit with different risk exposures, equation (24) decomposes the credit yield into a systematic risk component and a firm-specific risk component.

When $\lim _{\tau \rightarrow 0} Y^{*}(t, \tau)=\Lambda_{0, n}+\Lambda_{r, n} r(t)+\Lambda_{x, n} X_{n}(t)$. Letting $\tau \rightarrow \infty$, we obtain the asymptotic defaultable yield as: $Y^{*}(t, \infty)=\Lambda_{0}-\frac{\sigma_{r}^{2} \Lambda_{r}^{2}}{2 \kappa_{r}^{2}}+\mu_{z} \Lambda_{r}-\frac{\rho_{r, z} \sigma_{r} \sigma_{z} \Lambda_{r}^{2}}{\kappa_{r} \kappa_{z}}-\frac{\sigma_{z}^{2} \Lambda_{r}^{2}}{2 \kappa_{z}^{2}}+\Lambda_{x} \mu_{x}-\frac{\sigma_{x}^{2} \Lambda_{x}^{2}}{2 \kappa_{x}^{2}}-$ $\frac{\rho_{r, x} \sigma_{r} \sigma_{x} \Lambda_{x} \Lambda_{r}}{\kappa_{r} \kappa_{x}}$. Our three-factor model of defaultable bonds offers the flexibility to produce various defaultable yield curve shapes including double humped yield curve. 
The price of the defaultable coupon bond can now be computed by inserting (16) into (9). In particular, the yield to maturity on a defaultable coupon bond, $Y(t, \tau)$, can be recovered by solving the following non-linear equation:

$$
0=P(t, \tau)-\int_{0}^{\tau} c(t+u) \exp [-Y(t, \tau) u] d u-F \exp [-Y(t, \tau) \tau]
$$

which is, in principle, solvable given coupon bond price and the promised cash flow stream (one for each $\tau$ ). The yield curve of the defaultable coupon bond inherits the same structure as that displayed by the zeros.

Before closing this section, we discuss proxies for the firm-specific distress factor used in the study. Five candidates for $X_{n}(t)$ are selected for their empirical plausibility. Each choice is a dimensionless quantity and leads to a distinct testable model of credit risk. We later summarize how well these variables explain the cross-section of corporate yields. This analysis shows that the proposed variables have incremental information on corporate yields. Each firm-specific distress factor is discussed in turn:

1. Assume that $X_{n}$ is firm leverage. Standard corporate finance theory suggests that leverage captures firm-level distress. Leverage is also a key ingredient in the structural models of Merton (1974), Longstaff and Schwartz (1995) and Collin-Dufresne and Goldstein (1999). We will refer to this model as the Leverage Ratio Model.

2. Let $X_{n}$ be the ratio of a firm's book value of equity to its market value (i.e., Book-toMarket). According to Fama and French (1992), firms with high book-to-market are relatively more distressed. In contrast, firms with low book-to-market are stronger firms with good cash flow prospects. This model will be referred to as the B/M Ratio Model.

3. The next candidate for $X_{n}$ is the Profitability of a firm. This variable reflects the ability of a firm to honor debt obligations out of its operating income (Titman and Wessels (1988)). In this model, default probability is inversely related to profitability. Credit risk models that incorporate profitability concerns will referred to as the Profitability Model.

4. For the fourth model, we assume that $X_{n}$ is driven by the lagged credit spread (in the spirit of Duffie and Singleton (1997)). We will refer to this model as the Lagged Spread Model.

5. Finally, $X_{n}$ is the scaled stock price s(t), i.e., $s(t) \equiv \log (S(t) / b(t))$. In this case, we posit $d s(t)=-\frac{1}{2} \sigma_{x}^{2} d t+\sigma_{x} d \omega_{x}(t)$, which is a parametric special case of (15). The resulting credit risk model has 11 parameters. The use of equity prices is especially attractive from the 
hedging perspective (Madan and Unal (1998)). We will refer to this credit risk model as the Stock Price Model.

As already mentioned, when $\Lambda_{x}$ is set equal to zero, the credit risk model reduces to a twofactor model where movements in the treasury curve are the sole source of credit risk. Because of this property, the model with $\Lambda_{x}=0$ will be used to benchmark the performance of the above alternative credit risk models. The general model (11) is comparable to Duffee (1999). But in the interest of evaluating the out-of-sample pricing and hedging performance of credit risk models, we replace hidden factors by identifiable factors.

To limit the scope of our investigation, we restrict our attention to the class of reduced-form defaultable discount rate models. First, as default is triggered only at maturity, the Merton (1974) model cannot be easily adapted to price defaultable coupon bonds. Second, unless jumps are added, these models imply a counterfactually low credit spreads for short-maturity defaultable bonds. On the other hand, Collins-Dufresne and Goldstein (1999) have shown that the structural models in the one-factor class have undesirable long-run yield properties. Furthermore, Jones, Mason, and Rosenfeld (1984), Wei and Guo (1997) and Eom, Helwege, and Huang (2000) present evidence rejecting such models. In summary, our focus is on reduced-form default risk models with identifiable economic factors that may or may not be tradable.

\section{The Data on Defaultable Coupon Bonds}

The data for the study is merged from several sources. First, corporate coupon bond prices, yields and treasury security prices are extracted from the Lehman Brothers Fixed Income Database. This database has over 28,000 instruments and contains information on publicly traded nonconvertible debt, with principal in excess of one million dollars. For each fixed income security, the database has entries on, among others, (i) the month-end flat price, (ii) the accrued interest, (iii) the maturity date, (iv) the amount of coupon and principal, and ( $v$ ) the yield to maturity. Debt issues are classified as callable, putable, or subordinated (or having a sinking fund provision). Each debt contract is assigned an industry classification and a credit rating (Fitch, Moody's and Standard and Poor's). In this study, we employ the Standard and Poor's credit rating. The database covers the period from January 1973 to March 1998.

Several exclusionary filters are imposed to construct the sample of defaultable coupon bonds. First, trader bid quotes are used in our analysis (ask quotes are not recorded). Because the secondary market for corporate bonds is relatively illiquid, traders are often unwilling to supply quotes in the presence of insufficient trading. For these illiquid bonds, matrix quotes are generated 
(according to some internal model by Lehman Brothers) and recorded in the database. Since our primary goal is to test the performance of credit risk models against market prices, matrix quotes are avoided.

Second, bonds with embedded options are discarded. We also eliminated such bonds as passthrough and asset-backed securities. For consistency, only regular bonds are considered. To mitigate market microstructure biases, debts with time-to-maturity less than 1 year are excluded. Next, we only include bonds that pay semi-annual coupons. In fact, only a few defaultable discount bonds and quarterly/annual coupon paying bonds exist in the database. Finally, to facilitate model implementation, we retained firms with at least four bond issues outstanding each month and data availability of over two years. 183 firms satisfy all the above requirements.

The resulting firm universe is matched with equity price and accounting data from CRSP and COMPUSTAT, respectively. Due to the unavailability of equity price, 80 firms were dropped. Of the remaining 103 firms, 10 firms have data missing on leverage and book-to-market. We are therefore left with a final sample of 93 firms. This sample is broadly diversified with 24 financials, 48 industrials and 21 utility firms. Prior to March 1989, as few non-callable bonds were issued, the data is sparse with only 20 firms per month. In the interest of a wider cross-section, we decided to limit attention to the sample between March 1989 and March 1998. Our sample includes such well-known companies as Bank of America, Ford, IBM, Philip Morris, and Wal-Mart. This sample has 46,262 coupon bond observations.

The three-month treasury bill rate is the proxy for the short interest rate throughout (source: Federal Reserve Board). We employ trader quotes on treasury STRIPS to build the term structure of default-free bonds. There are 20,173 treasury STRIPS quotes over our sample period (about 135 treasury prices per month). We use treasury STRIPS to estimate the two-factor model of interest rates.

To empirically test credit risk models, we constructed several proxies for the distress factor, $X_{n}(t)$. These variables are constructed as described below:

Leverage, $\operatorname{Lev}_{n}(\mathrm{t})$, is defined as long-term book value of debt (COMPUSTAT quarterly item 51 ) divided by the firm value. The firm value is the sum of long-term debt and the market capitalization of common equity, M;

Book-to-Market, $\mathrm{B}_{n}(\mathrm{t}) / \mathrm{M}_{n}(\mathrm{t})$, is computed as the book value of equity (COMPUSTAT quarterly item 59) divided by the market value of equity;

Profitability, Profit ${ }_{n}(\mathrm{t})$, is calculated as operating income (COMPUSTAT quarterly item 21) divided by net sales (COMPUSTAT quarterly item 2); 
$\operatorname{Spread}_{n}(t-1)$, is the average yield on the firm's debt minus the three-month treasury bill rate, as of month $\mathrm{t}-1$;

Scaled Stock Price, $s_{n}(t)$, is the log of the current stock price normalized by the money market account. That is, $s(t) \equiv \log \left(\frac{S(t)}{[1+r(0)] \times[1+r(1)] \cdots[1+r(t)]}\right)$.

Even though long-term debt and book values are recorded at the quarterly frequency, the series for leverage and book-to-market ratio are monthly. For each firm, the debt value and the book value are updated on a quarterly basis (while the market value of equity is updated monthly). To circumvent any look-ahead biases, we use debt and book values from the previous quarter to compute leverage and book-to-market factors for the next three months. A cubic spline is used to convert the quarterly profitability measure into a monthly profitability measure.

Corporate bonds are classified into three credit rating categories. Specifically, bonds with (numerical) credit rating up to 5 are designated as $A A$-rated; between 6 and 8 are designated as A-rated; and credit rating 9 and higher are designated as BBB-rated (or below). Moreover, bonds with maturity less than 5 years are called short-term bonds; between 5 and 10 years are classified as medium-term bonds; and maturity longer than 10 years form the long-term bond category. Table 1 shows that 15\% (53\%) of the bond issues have a credit rating of AA (A), while $32 \%$ have a credit rating of BBB or below (see Duffee (1999) and Elton, Gruber, Agrawal, and Mann (20001)).

Table 1 displays summary statistics on bond attributes and firm-specific distress factors (i.e., leverage, B/M and profitability) for 25 firms. We report the (average) number of bonds outstanding, the yield, the credit rating, and the maturity. The maturity structure of bonds is mixed with some firms preferring short-term debt to its long-term counterpart. According to Table 1, firms in the financial industry tend to have the lowest maturity, while industrials tend to finance long-term. Likewise, more credit-worthy firms issue longer-term debt. The average credit spread between AA and BBB-rated bonds is 58 basis points.

Turning to firm-specific distress factors, notice that leverage, B/M and profitability vary substantially in the firm cross-section. On average, less credit worthy firms are associated with higher leverage and a more pronounced book-to-market ratio (and vice-versa). However, the yield pattern is less than clear across industries: industrials have the highest average yield but relatively lower leverage and $\mathrm{B} / \mathrm{M}$. The relationship between average profitability and average yield appears ambiguous. That is, a higher profitability need not translate into lower credit yields.

Four empirical yardsticks are adopted to evaluate credit risk models. At the outset, we determine whether firm-specific distress factors have explanatory ability in the cross-section of yields. In a second exercise, we analyze whether the estimated structural parameters are reasonable and investigate the in-sample fitting errors of credit risk models. Next, we contrast their out-of-sample 
pricing accuracy. Finally, we take risk management perspectives and examine the hedging effectiveness of credit risk models. Each yardstick captures distinct aspects of model performance.

\section{Firm-Specific Distress Factors and the Cross-section of Yields}

Although the choice of firm-specific distress factors appears reasonable on economic grounds, we examine whether cross-sectional variations in these variables explain differences in the corporate yields. The basic testing equation is:

$$
Y_{\ell}(t)=\Pi_{0}(t)+\Pi_{1}(t) \tau_{\ell}(t)+\Pi_{2} X_{\ell}(t)+\epsilon_{\ell}(t), \quad \ell=1, \cdots, L,
$$

where $\ell$ ranges over all bond issues of all the names and $\mathrm{t}=1, \cdots, \mathrm{T}$. In the regression specification (26), $\tau_{\ell}$ denotes term-to-maturity of bond $\ell, Y_{\ell}$ is the corresponding yield and $X_{\ell}$ is the distress factor (leverage, book-to-market or profitability). The OLS regression is performed each month, $t$, and the resulting coefficients are pooled in the time-series (i.e., the reported $\Pi_{2} \equiv \frac{1}{T} \sum_{t=1}^{T} \Pi_{2}(t)$ ). The testable hypothesis is that higher levels of leverage and book-to-market (and lower levels of profitability) lead to higher corporate yields. That is, more distressed firms have higher credit spreads. Shown in square brackets, the reported t-statistic is the mean coefficient divided by the standard error of the mean estimate.

The $\Pi_{2}$ estimate, reported in Table 2, is at the core of the defaultable discount rate specification (11). Panel A of Table 2 demonstrates that the impact of leverage on yields is consistently positive and strongly significant. The coefficient $\Pi_{2}$ varies between 0.23 and 1.98 when bonds are grouped by credit rating; and between 0.72 and 1.38 when bonds are grouped by maturity. For the set of regressions, the minimum t-statistic is 5.4. Consistent with intuition, the effect of leverage on yields is most pronounced among lower grade bonds and among long-term bonds. For instance, a $1 \%$ change in the leverage ratio increases the yield of BBB-rated bonds by 19.8 basis points. The impact of leverage on yields is time-stable, as reflected in the proportion of t-statistics above 2 (i.e., as seen by $1_{t>2}$ ). Moreover, the goodness-of-fit of the model is reasonable: for BBB-rated bonds, the maximum (adjusted) $R^{2}$ is $87 \%$ in the bivariate regression with $\tau_{\ell}$ and $\mathrm{Lev}_{\ell}$ as the explanatory variables (and $10.2 \%$ in the univariate regression with $\mathrm{Lev}_{\ell}$ ).

Turning to the yield behavior with respect to book-to-market, we observe a similar finding: the $\mathrm{B} / \mathrm{M}$ attribute is positively correlated with average yields (see Panel B). Consider BBB-rated bonds. The coefficient $\Pi_{2}$ is 0.24 with a t-statistic of 5.5. Now consider long-term bonds, where the estimated $\Pi_{2}$ is 0.55 (t-statistic of 7.7 ). Like leverage, the coefficient $\Pi_{2}$ is monotonically increasing with bond maturity. The magnitude of $1_{t>2}$ suggests that the effect of book-to-market 
remains robust over time. However, comparing Panels $\mathrm{A}$ and $\mathrm{B}$, one difference is apparent. Once the maturity of the bond is controlled, the book-to-market factor displays smaller slope coefficients. Economically, a 1\% change in the book-to-market factor implies a 5.5 basis points change in the yield of long-term bonds (the leverage counterpart is 13.8 basis points). Overall, the book-tomarket factor is an important variable in the cross-section of corporate yields.

As expected, Panel $\mathrm{C}$ indicates that the average $\Pi_{2}$ is negative. The coefficient $\Pi_{2}$ ranges between -1.70 and -0.16 . As in the case of leverage, the profitability measure has a bigger effect on long-term bonds and low-rated bonds. Based on the $1_{t<-2}$ statistic, the evidence is less than strong for profitability. This is also confirmed by the relatively low magnitudes of the t-statistic and the goodness-of-fit $\mathrm{R}^{2}$ measures. Our evidence indicates that profitability may be of second-order importance relative to leverage and $\mathrm{B} / \mathrm{M}$ ratio.

The coefficient $\Pi_{1}$ can be interpreted as the slope of the corporate yield curve. Irrespective of the distress factor, the yield curve is steeper for lower-rated bonds and for short-term bonds. $\Pi_{0}$, the unconditional instantaneous yield, is positive and statistically significant. Our empirical findings on the relevance of distress factors are robust across sub-periods (not reported). This is true even when $Y_{\ell}(t)-r(t)$ is employed as the dependent variable in (26).

In sum, the regression results are broadly consistent with our modeling approach that the defaultable discount rate is a function of firm-specific distress factors. Even after accounting for credit rating, the marginal impact of firm-specific distress factors on yields is generally significant. Overall, firm-specific variables are informative about cross-sectional variations in the credit spreads. Having justified our choice empirically, we now proceed to a more formal analysis of credit risk models and to investigating the determinants of default risk.

\section{$5 \quad$ Estimation of Credit Risk Models}

Guided by theoretical and practical considerations, six credit risk models are estimated. The specification of the defaultable discount rate is as outlined below $(n=1, \cdots, N)$ :
1. Leverage Ratio Model
$R_{n}(t)=\Lambda_{0, n}+\Lambda_{r, n} r(t)+\Lambda_{x, n} \operatorname{Lev}_{n}(t)$
2. B/M Ratio Model
$R_{n}(t)=\Lambda_{0, n}+\Lambda_{r, n} r(t)+\Lambda_{x, n} \frac{B_{n}(t)}{M_{n}(t)}$
3. Profitability Model
$R_{n}(t)=\Lambda_{0, n}+\Lambda_{r, n} r(t)+\Lambda_{x, n} \operatorname{Profit}_{n}(t)$
4. Lagged Yield Spread Model
$R_{n}(t)=\Lambda_{0, n}+\Lambda_{r, n} r(t)+\Lambda_{x, n} \operatorname{Spread}_{n}(t-1)$
5. Stock Price Model
$R_{n}(t)=\Lambda_{0, n}+\Lambda_{r, n} r(t)+\Lambda_{x, n} s_{n}(t)$
6. Interest Rate Model
$R_{n}(t)=\Lambda_{0, n}+\Lambda_{r, n} r(t)$ 
where, recall, $\operatorname{Lev}_{n}(t)$ is the leverage ratio; $\frac{B_{n}(t)}{M_{n}(t)}$ is the book-to-market ratio; $\operatorname{Profit}_{n}(t)$ represents the firm profitability; $\operatorname{Spread}_{n}(t-1)$ is the lagged credit spread; and $s_{n}(t)$ is the scaled stock price. In each case, the defaultable discount (coupon) bond price can be determined from equation (16) $((9))$. Our discussion is divided into three parts: (i) estimating the interest rate parameters, (ii) estimating the firm-specific default parameters, and (iii) contrasting the in-sample valuation errors across models.

\subsection{Interest Rate Parameters}

The parameters of the interest rate process are common to all firms. For this reason, we only employ treasury securities to estimate the interest rate parameters (see also Duffee (1999)). In particular, we exploit a panel of treasury STRIPS prices. The resulting interest rate parameters are fixed in the cross-section of firms. The exact implementation procedure is as follows.

Step A. Collect L treasury STRIPS prices each month. Let $\tau_{\ell}(\ell=1,2, \cdots, L)$ index the termto-maturity of the treasury STRIPS. Denote the market price by $\bar{B}\left(t, \tau_{\ell}\right)$ and the model price by $B\left(t, \tau_{\ell}\right)$. Let the complete vector of structural parameter (under the equivalent martingale measure) be defined as $\Phi_{r} \equiv\left\{z, \kappa_{r}, \sigma_{r}, \kappa_{z}, \mu_{z}, \sigma_{z}, \rho_{r, z}\right\}$. For each STRIPS $\ell$, define the valuation error:

$$
\epsilon_{\ell}\left[\Phi_{r}\right] \equiv \frac{\bar{B}\left(t, \tau_{\ell}\right)-B\left(t, \tau_{\ell}\right)}{\bar{B}\left(t, \tau_{\ell}\right)},
$$

which is the percentage deviation of the model determined price from the observed market price.

Step B. Solve for the parameter vector $\Phi_{r}$ that minimizes the root mean-squared percentage pricing error (one for each month $t$ ):

$$
\operatorname{RMSE}_{r}(t) \equiv \min _{\Phi_{r}} \sqrt{\frac{1}{L} \sum_{\ell=1}^{L}\left|\epsilon_{\ell}\right|^{2}}, \quad t=1, \cdots, T .
$$

This minimization procedure will result in an estimate of the risk-neutralized parameters for the two-factor interest rate model. The implied parameter approach is now standard in the literature (see Brown and Dybvig (1986) and Dai and Singleton (2000) and references therein). The variation across time in the risk-neutral parameters is consistent with the traditional asset pricing results on the time-variation of the risk premia in the financial markets.

Note that the one-factor model of interest rates is nested within the two-factor model of interest rate outlined in (12)-(13). Setting $\kappa_{z}=\sigma_{z}=0$ and fixing $\mathrm{z}$ to be a constant, we obtain the one-factor (Vasicek (1977)) model of interest rates: $d r(t)=\kappa_{r}[z-r(t)] d t+\sigma_{r} d \omega_{r}(t)$. Imposing appropriate restrictions on the parameter vector in (27)-(28), we can similarly infer the parameters 
of the one-factor model. In Panel A and Panel B of Table 3, we present the parameter estimates and compare the in-sample and out-of-sample valuation errors of the one-factor and the two-factor model of interest rates, respectively.

The empirical estimations are enlightening from several perspectives. Because the estimation results are similar across subsamples, concentrate on the full sample findings. First, adding a stochastic mean factor to the one-factor model of interest rates improves its performance considerably. This point can be demonstrated in several ways. Inspection of the table shows that the in-sample RMSE of the one-factor model is $1.64 \%$, while the corresponding RMSE for the two-factor model is $0.51 \%$. The reduction in the in-sample absolute yield errors, denoted BYE, is also substantial: the two-factor model provides an average absolute yield error of 6.75 basis points versus 14.91 basis points (hereby bp) for the one-factor model. Viewed from a valuation perspective, the $8.16 \mathrm{bp}$ improvement is economically important (Table IV in Dai and Singleton (2000) provides a comparison).

Not surprisingly, the superiority of the two-factor model of interest rates is also evident on the basis of out-of-sample goodness-of-fit measures. To compute the out-of-sample valuation errors, we initially estimate $\Phi_{r}$ from treasury STRIPS observed as of month $t-1$. We then use these structural parameters (and $r$ ) to calculate the theoretical price of STRIPS in the subsequent month $t$. Comparing the model price to the market price and consolidating the valuation errors across all STRIPS, we report the average out-of-sample RMSE and BYE (in their respective columns) in curly brackets. We can observe that a two-factor (one-factor) model of interest rate has an out-of-sample RMSE of $2.82 \%(3.35 \%)$ and an out-of-sample BYE of 20.82 (24.70) basis points. In a nutshell, based on the in-sample and out-of-sample valuation yardsticks, the two-factor model of interest rates is less mis-specified. Therefore, the two-factor interest rate model will be adopted to estimate the credit risk models throughout.

As seen, the structural parameters of the two-factor (and one-factor) model of interest rates are reasonable. Over the full sample, the average long-run mean, z, is $8.5 \%$ with a drift coefficient of $15.8 \%$ and a diffusion coefficient of 0.019 . The speed of adjustment of $\mathrm{r}$ and $\mathrm{z}$ to their means is 0.301 and 0.032 , respectively. We estimate a negative correlation between interest rate movements and changes in the long-run mean. Albeit estimated under the physical probability measure, CollinDufresne and Solnik (1999, Table 1) report similar estimates for the two-factor model (see also, among others, Chen and Scott (1993) and Dai and Singleton (2000)).

The estimated parameters seem time-stable. This can be seen by both the small standard errors of the parameter estimate (shown in parenthesis) and the relatively small variation in the parameter estimates from the 89:03-93:12 subsample to the 94:01-98:03 subsample. Moreover, the coefficient of variation, computed as the standard deviation of the estimate divided by mean 
estimate, are all less than 0.5. Other parameters of the credit risk models, as we describe next, are conditional on the estimated interest rate parameters.

\subsection{Firm-Specific Default Parameters}

The remaining task is to estimate the parameters of the defaultable discount rate and the parameters of the distress process. Take the leverage ratio model as an example and define the firmspecific parameters by the vector: $\Phi_{x, n} \equiv\left\{\Lambda_{0, n}, \Lambda_{r, n}, \Lambda_{x, n}, \kappa_{x, n}, \mu_{x, n}, \sigma_{x, n}, \rho_{r, x, n}: n=1, \cdots, N\right\}$. As before, we minimize the root mean-squared percentage pricing error:

$$
\operatorname{RMSE}_{x, n}(t) \equiv \min _{\Phi_{x, n}} \sqrt{\frac{1}{K} \sum_{k=1}^{K}\left|\epsilon_{x, k, n}\right|^{2}}, \quad t=1, \cdots, T \text { and } k=1, \cdots, K,
$$

where letting $\epsilon_{x, k}\left[\Phi_{x, n}\right] \equiv \frac{\bar{P}\left(t, \tau_{k}\right)-P\left(t, \tau_{k}\right)}{\bar{P}\left(t, \tau_{k}\right)}$. Here, $\bar{P}(t, \tau)$ is the market price of the defaultable coupon bond while $P(t, \tau)$ is the theoretical price implicit in the leverage ratio model.

While there is an abundance of treasury STRIPS, the number of defaultable coupon bonds is often insufficient to estimate the 7 structural parameters contained in $\Phi_{x, n}$. To achieve a compromise, we modify our approach in an elementary way. We pool corporate bonds each quarter and then minimize (29), which has the implication of asserting the constancy of risk premia for a quarter. Lengthening the period of estimation is subject to greater mis-specification. This estimation procedure is repeated for each firm and for each of the six credit risk models.

In summary, the estimation of each credit risk model is carried in two phases: (1) The parameters of the two-factor interest rate model are estimated from treasury STRIPS. (2) Conditional on the estimated treasury parameters, the parameters of the defaultable discount rate and the distress factor are estimated from individual corporate bonds. In other words, the parameters of the defaultable discount rate are updated only once every three months, while the structural parameters driving treasury are updated each month.

In reporting the parameter estimates of credit risk models, two decisions are made to conserve on space. First, we only present the parameter estimates for the leverage ratio model and the $\mathrm{B} / \mathrm{M}$ ratio model. Second, rather than report parameter estimates for each firm, we aggregate parameter estimates by their credit rating, maturity and industrial classification, respectively. In doing the aforementioned, the parameters are first averaged in the time-series for each firm and then across firms. Naturally, the large number of firms in our sample makes it impractical to display parameter estimates at the individual firm level.

Table 4 presents the average value and the coefficient of variation for each parameter in $\Phi_{x}$. Start with the leverage ratio model in Panel A. Strengthening our priors from the cross-sectional 
regressions, the coefficient $\Lambda_{x}$ is positive. The average $\Lambda_{x}$ across all the firms and time periods is 0.0051 (although not reported, it is statistically significant for most individual firms). Consequently, in the presence of interest rate risk, the marginal effect of leverage is to enhance the defaultable discount rate. Corporate yields and credit spreads accordingly rise when firm leverage increases dynamically over time. Of particular interest is the fact that $\Lambda_{x}$ is highest among AA-rated bonds and the lowest among utility firms. Along the maturity spectrum, the magnitude of the estimate indicates that leverage related distress is more relevant for long-dated corporate bonds than for short-dated corporate bonds.

With regard to the role of interest rate risk in the defaultable discount rate, the sign of $\Lambda_{r}$ is positive and less than unity. Specifically, the lower the credit rating of the bond, the more positive is the parameter estimate: $\Lambda_{r}$ equals 0.767 for AA-rated bonds, 0.823 for A-rated bonds and 0.874 for BBB-rated bonds. As in Duffee (1999), the parameter estimates substantiate the common intuition that an upward shift in the short rate raises the defaultable discount rate. Our evidence reveals that the effect of interest rate is generally the strongest among short-term bonds. Comparing the coefficient of variation for $\Lambda_{r}$ versus $\Lambda_{x}$, we note that the $\mathrm{CV}$ for interest rate (distress) sensitivity is mostly less (more) than 0.5 . The response of defaultable discount rate to a changing interest rate environment is more uniform relative to changing firm-specific distress risk.

During our sample period, the average estimate of the instantaneous credit yield, $\Lambda_{0}$, ranges between $1.8 \%$ for AA-rated bonds and $2.3 \%$ for BBB-rated bonds. Consequently, as previously asserted, $\Lambda_{0}$ is monotonically increasing when the credit rating worsens. Consistent with the observed yield structure of corporate bonds, the instantaneous credit yield is higher for long-term bonds relative to short-term counterparts. On balance, the estimated parameters $\Lambda_{0}, \Lambda_{r}$ and $\Lambda_{x}$ are each plausible. As theory requires, the defaultable discount rate is positive in general (given the positivity of $r(t)$ and $\operatorname{Lev}(t))$.

Now shift focus to the forcing process for a firm's leverage. The data supports the idea that leverage is a mean-reverting stochastic process: the average $\mu_{x}$ is $46.4 \%$ for AA-rated bonds and $47.9 \%$ for BBB-rated bonds (and statistically significant with $\mathrm{CV}$ far below 0.5 ). Regardless of the credit rating and bond maturity, the speed of adjustment is remarkably stable. The average $\kappa_{x}$ is in the neighborhood of 0.26 and implies a half-life of 2.65 years. The volatility parameter, $\sigma_{x}$, is about $12 \%$ and $\rho_{r, x}$ is in the range of -0.115 to -0.10 . The small RMSE and APE (less than $2 \%$ ) suggests that the adopted one-factor specification may be a reasonable candidate for characterizing the risk-neutral dynamics of the leverage ratio.

When distress is proxied by book-to-market, the structural parameters are similar (and reported in Panel B of Table 4). We again reach the conclusion that the magnitude of $\Lambda_{x}$ is small relative to the magnitude of $\Lambda_{r}$. Allowing for possible scaling differences in the nominal interest 
rate and the firm-specific distress factors, one interpretation of this finding is that the interest rate risk component may be of higher-order relevance. We also divided the full sample into two subsamples and found average parameters close to those presented in Table 4. The subsample results and parameter estimates from other credit risk models are available upon request.

\subsection{Comparison of In-Sample Valuation Errors}

Because credit risk models are often employed in marking-to-market other illiquid securities, the in-sample performance is of interest. Does a three-factor credit risk model with identifiable firmspecific distress factors improve upon a two-factor counterpart with firm-specific distress considerations absent? Table 5 provides a snap-shot of in-sample valuation errors across the two dimensions of credit rating and maturity. For each credit risk model, we provide the average (minimized) RMSE and the corresponding average BYE valuation errors. The results from this line of investigation are summarized below:

1. Overall, the inclusion of firm-specific distress factors provide only a marginal improvement over the interest rate credit risk model. Contrary to our expectations, based on the minimized RMSE, the maximum improvement is of the order of $0.17 \%$ (in the intersection of AA-rated and long-term bonds). The maximum difference in absolute yield errors, BYE, amounts to 2.31 basis points (across all models). The systematic distress factor is an important source of credit risk.

2. Among the set of credit risk models with a firm-specific distress factor, the stock price model is the least mis-specified in-sample. When averaged over the entire bond sample, the RMSE and BYE of this model is $1.26 \%$ and 20.52 basis points (compared the maximum errors of $1.35 \%$ and 21.62 ), respectively.

3. Controlling for maturity, the average BYE worsens with the credit rating of the bond (especially among medium-term bonds that are BBB-rated). The yield basis point errors are declining with maturity: all models face a particular hurdle fitting short-term bonds.

4. Even though leverage and $\mathrm{B} / \mathrm{M}$ factors are often identified with distress, the performance of the models do not depart substantively. In several credit rating-maturity groupings, the 8 parameter interest rate model has lower valuation errors relative to the more elaborately specified 13 parameter models. More complex models need not necessarily perform better in-sample.

There may be several reasons for the documented phenomenon that the discrepancy between the valuation errors from various credit risk models is small in magnitude. For one, the prevailing 
fixed-income databases are tilted towards investment grade bonds. For this class of bonds, it is entirely possible that systematic distress factors capture the first-order effect of default. Firmspecific default component may be more relevant for pricing speculative (high yield) bonds.

Second, the adopted practice of updating the parameter set potentially interacts with the illiquidity of the corporate fixed income market. At an abstract level, the frequent updating of the parameters can have the effect of reducing the valuation errors of all pricing models. Some of these concerns will be addressed in the empirical exercises to follow. It suffices to say that the nature of the in-sample findings have pushed us to understand the out-of-sample pricing and dynamic hedging performance of credit risk models in even greater detail.

\section{Pricing Accuracy of Credit Risk Models}

Out-of-sample pricing performance need not improve when additional parameters are added to a valuation model. This is because extra parameters have identification problems and may penalize out-of-sample accuracy. In the empirical analysis to follow, we first present an integrated picture of model performance when defaultable bonds are classified according to credit rating, maturity, industry affiliation, and individual firms. Second, a set of robustness checks are performed. Lastly, we present a specification analysis of model mispricing. Our fundamental emphasis continues to be on explaining variations in defaultable bond yields using firm-specific and systematic default factors.

\subsection{Consolidated Picture of Model Errors}

The implementation of the out-of-sample test is straightforward. To compute the time $t$ valuation errors, we first estimate the parameter vectors, $\Phi_{r}$ and $\Phi_{x, n}$, using the cross-section of STRIPS (previous month) and defaultable corporate bonds (in the previous quarter). Using parameters so estimated, we calculate the model determined bond price with contemporaneous interest rate and firm-specific distress factor as inputs. The long-run interest rate is set at its lagged value, as it is estimated within the parameter vector $\Phi_{r}$. Next we compute the absolute percentage pricing error, APE, as the absolute valuation error divided by the market bond price. A similar calculation is made for the absolute yield basis point error, BYE, defined as the absolute deviation of the model yield from the market observed yield. This procedure is repeated for every bond and for each firm. Allowing for possible departures in the number of structural parameters, a similar procedure is followed for other credit risk models.

Table 6 puts the out-of-sample pricing results into perspective. First, most three-factor credit risk models do better than the two-factor interest rate only model. For instance, measured by 
both the APE and BYE, the leverage ratio model and book-to-market ratio model consistently perform better than the interest rate model. Based on the entire bond sample, the improvement is not large in magnitude, however. More precisely, the difference between the $\mathrm{B} / \mathrm{M}$ ratio model and interest rate model is $0.03 \%$ based on the APE, and 0.67 basis points based on the BYE. Though, on the surface, the pricing improvement appears to be observationally small, given the large notional principal, it may still be economically relevant. In spirit of our findings, Gupta and Subrahmanyam (2000) also find low magnitudes of out-of-sample pricing errors in the cap and floor markets. The low pricing errors may be a feature common to most fixed income markets (also see Dai and Singleton (2000) and Duffee (1999)). In our case, the maximum APE and BYE in the "All-All" category is $1.88 \%$ and $33.41 \mathrm{bp}$, respectively.

Second, comparing the entries in Table 5 and Table 6, it is not surprising that the out-ofsample valuation errors are strictly higher than the corresponding in-sample valuation errors. The deterioration in model valuations amount to about 6 basis points when averaged over all bonds, and about 9 basis points among BBB-rated bonds. Because the ask price is not reported in the Lehman database, we are unable to compare the valuation errors relative to the bid-ask spreads. In a later exercise, we provide a specification analysis of pricing errors (especially after controlling for credit rating and maturity effects).

Unlike our findings from in-sample pricing errors, third, the stock price model has the worst performance out-of-sample (in all credit rating and maturity groupings). The BYE (APE) of this model ranges between 26.36 bp to 38.69 bp $(0.91 \%$ to $3.34 \%)$ compared to 24.21 bp to 42.62 bp $(0.62 \%$ to $2.64 \%)$ for the interest rate model. This potential inconsistency may be related to the substantial volatility of equities relative to corporate yields. Therefore, the use of scaled stock price produces unwanted volatility in the defaultable discount rate. However, in the hedging section, we show that the stock price is effective in explaining price changes. Finally, even though the out-of-sample performance of the leverage, B/M, profitability, and the lagged spread, models is close, the relative ranking between credit risk models is altered in-sample versus out-of-sample.

Fourth, the model mispricing displays systematic biases across credit rating and maturity. The principal evidence is outlined below:

- The absolute yield basis point errors are generally higher for lower rated bonds. In the case of the leverage ratio model, the difference between the pricing errors for AA-rated versus BBB-rated bonds is about $8 \mathrm{bp}$. They are also higher for shorter maturity bonds, with a difference of about $7 \mathrm{bp}$;

- Consider model performance across the maturity dimension. Based on the APE yardstick, the $\mathrm{B} / \mathrm{M}$ ratio model has the best performance. When the $B Y E$ valuation errors are the 
basis, the $\mathrm{B} / \mathrm{M}$ is also the best model for short-term and medium-term bonds. In contrast, the profitability model produces the lowest BYE fitting errors among long-term bonds;

- Now consider the rating dimension. Both the $\mathrm{B} / \mathrm{M}$ ratio model and the leverage ratio model are superior models compared to the interest rate model for AA-rated and A-rated bonds. The reverse conclusion holds true for BBB-rate bonds;

- Returning to long-term bonds, the difference in BYE between the leverage ratio model (and also B/M, lagged spread and profitability models) and the interest rate only model is more than 2 bp. In particular, the small overall difference between the credit models with and without firm-specific variables is mainly due to their close performance in the short and medium term category;

- Rarely is the lagged spread model superior to the leverage ratio model and the $\mathrm{B} / \mathrm{M}$ ratio model. Overall, leverage and book-to-market factors enhance the working of the credit risk model.

The average mispricing patterns for each credit risk model warrant a few comments. Figure 1 and Figure 2 displays the mean yield basis point error by credit rating and maturity. From Figure 1 and "All Bonds," we can make the observation that (with the exception of the stock price model) all credit risk models over-price the market observed yield. Moreover, the interest rate model has the worst average over-pricing of $6.93 \mathrm{bp}$. On the other hand, A-rated and BBB-rated bonds are underpriced by the stock price model. The mispricing worsens as the rating decreases. A different mispricing pattern emerge across maturity: all models over-price short-term bonds and under-price medium-term bonds. The credit risk models behave differently in the long-term bond category with leverage and $\mathrm{B} / \mathrm{M}$ models over-pricing, while the interest rate model under-prices.

Moving on to Panel A of Table 7, we first report the out-of-sample pricing and yield performance, by industry. While the conclusions regarding the relative ranking of alternative credit risk models essentially hold, one additional insight emerges. That is, most models fit the utility bonds the best, followed by industrial and then financial firms. However, this conclusion must be interpreted with caution, as considerations of bond maturity and cash flow stability vary across industries. For example, stable operating cash flows may translate into a lower default probability for utilities.

Panel B of Table 7 demonstrates that the differences between credit risk models surface more clearly when the pricing error is considered at the individual firm level. Specifically, we show that firm-specific distress factors have explanatory ability beyond systematic distress factors. Among our sample of 93 firms, we observe that the leverage ratio model outperforms the interest rate 
model for $71 \%$ of the firms; the corresponding figures for book-to-market ratio model and the lagged spread model is $66 \%$ and $69 \%$, respectively. Pair wise comparison of the leverage ratio model and the book-to-market ratio models shows that the former outperforms the latter for $51 \%$ of the firms. Hence, the two models have a comparable relative performance.

By far, one surprising result is the small improvement made by the lagged spread model over the interest rate model. This model uses the lagged average spread in explaining the current spread. The empirical outcome is therefore puzzling from an autoregressive viewpoint. In summary, firmspecific characteristics, especially leverage ratio and book-to-market equity ratio help lower the out-of-sample pricing errors. Contrary to what one might expect, even the worst performing models (the stock price and profitability models) have a relative small out-of-sample pricing error. The class of credit risk models considered have performance adequate for marking risk exposures.

\subsection{Robustness}

How robust are our empirical findings to perturbations in test design? To address this question, several empirical exercises are conducted. In the first experiment, we divided the full sample period into two subsamples. The yield basis point errors for the 1994-1998 subsample (shown in Table 8) confirms that modeling interest rate risk is of fundamental importance. Albeit the BYE are lower over this subsample, the maximum improvement by any credit risk model over the interest rate model in the "All" category is about 0.5 basis points. It is reassuring that BYE again displays a U-shaped maturity pattern, with BYE of the short-term bonds typically more pronounced than the long-term bonds.

Because the median can be a more robust statistic, we compute the median BYE across firms each month; the reported median BYE is the average median in the time-series. Comparing the corresponding entries in Table 8 and Table 6 , the medium BYE is generally smaller than the mean. For instance, the median BYE for the interest rate (leverage ratio) model is $23.98 \mathrm{bp}$ (23.42 bp) versus $28.07 \mathrm{bp}(27.60 \mathrm{bp}$ ) for the mean. Our discussions about credit risk models are not dependent on the choice of the measure of central tendency. In particular, the documented results are not overly influenced by either aggregation or the existence of outliers.

One remaining concern is the consequence of frequently updating structural parameters on model performance. To investigate this question, we took a rather extreme approach. In this empirical exercise, we time-averaged the structural parameter values and kept them constant over the entire sample of 89:03 through 98:03. Recall that the constancy of the risk-neutral parameters is tantamount to the constancy of the risk premia, which is counterfactual. Then, updating values for the nominal interest rate, the firm-specific distress factor and the stochastic long-run mean 
interest rate, we recomputed the pricing errors for all the bonds. In the last panel of Table 8 , we report the resulting yield basis point errors. We can again make the point that the yield basis point errors are monotonically increasing when credit-worthiness of the bonds worsens. It is evident that firm-specific variables have incremental power in explaining the yield structure of corporate bonds: the leverage ratio model and the $\mathrm{B} / \mathrm{M}$ ratio model now out-performs the interest rate model by a wider margin. In large part, our central findings are unaffected by how the structural parameters are updated. The empirical results are mostly robust.

\subsection{Specification Analysis of Pricing Errors}

Two key issues are addressed in this subsection. First, are model biases - pooled by credit rating or maturity - linked to dynamic variations in certain systematic distress factors? Second, are cross-sectional variations in model errors related to excluded firm-specific factors? Each issue is elaborated in turn.

To investigate whether the unexplained portion of the pricing error is due to systematic distress factors other than the short interest rate, the following OLS regression is estimated:

$$
\operatorname{APE}(t)=\eta_{0}+\eta_{g} \operatorname{GIP}(t)+\eta_{p} \operatorname{TERM}(t)+\eta_{d} \operatorname{DEF}(t)+\epsilon(t)
$$

for each credit risk model. In equation (30), GIP(t) is the growth rate of industrial production (during month $t$ ); TERM(t), the term premium, is the yield differential between the 30-year treasury bond and the three-month treasury bill rate; and $\operatorname{DEF}(\mathbf{t})$, the default premium, is the yield differential between BBB-rated bonds and AAA-rated bonds. Table 9 reports the results of the time-series regression, where the dependent variable, APE, is the equally-weighted absolute percentage pricing error over all bonds. The t-statistics are computed using robust standard errors.

Several points can be made based on this table. Consider the combined explanatory ability of the systematic factors. We can first make the observation that the goodness-of-fit $R^{2}$-statistics are higher for AA-rated bonds and medium-term bonds. Second, among credit risk models, the stock price model and the profitability model appear most mis-specified when ranked by their average $R^{2}$, across all categories. Therefore, if one were to consider expanding on the systematic factors, then the stock price model and the profitability model would benefit the most, especially in the medium-term category.

Regardless of the credit risk and the maturity of the bond, most of the credit risk models experience a deterioration in the pricing quality in periods of high industrial growth. This is inferred from noting that the coefficient $\eta_{g}$ is generally positive. It is also apparent that GIP impacts the pricing quality of AA-rated and short-term bonds the most. Continuing, periods of 
high term premium significantly impacts the pricing of short-term bonds. One possible explanation is that the adopted two-factor interest rate model performs adequately for medium and long-term bonds.

Our results broadly suggest that if the number of systematic factors was to be increased, then the default premium would be a good choice. As seen, the default premium is perhaps the most significant systematic distress factor. A rise in the default premium lowers the absolute pricing errors of AA-rated bonds. Among AA-rated bonds, we see that with the exception of leverage and $\mathrm{B} / \mathrm{M}$ ratio models, most model errors are significantly related to default premium. Among BBB-rated bonds, each credit risk modeling error is significantly related to DEF(t). So, including default premium in the defaultable discount rate specification can help mitigate the pricing errors of a credit risk model. If the default premium were to be introduced as a systematic distress factor, one would need to construct a zero-coupon credit spread curve that is rich enough to permit estimation of the risk-neutral default premium process. Currently, the data for such an exercise is not readily available. For these reasons, we have maintained focus on the interest rate factor throughout.

Let us now reconcile the second issue in some detail. Notice that, unlike with additional systematic factors, two firm-specific factors can be accommodated within our empirical framework (provided there are sufficient number of bonds). How can a credit risk model with two firmspecific factors be expected to fare relative to the set of one-factor models already estimated? In this regard, we explore two cross-sectional regression specifications. First, we regressed the absolute percentage pricing errors of the leverage ratio model on the $\mathrm{B} / \mathrm{M}$ ratio (all t-statistics are significant, and $\ell=1, \cdots, L)$, and obtained:

$$
\begin{array}{lll}
\text { All-Bonds } & \left.\mathrm{APE}_{\ell}\right|_{\mathrm{Lev}}=0.255+0.021 \frac{\mathrm{B}_{\ell}}{\mathrm{M}_{\ell}}+\epsilon_{\ell}, & R^{2}=5.6 \% \\
\text { BBB-Rated } & \left.\mathrm{APE}_{\ell}\right|_{\mathrm{Lev}}=0.283+0.019 \frac{\mathrm{B}_{\ell}}{\mathrm{M}_{\ell}}+\epsilon_{\ell} & R^{2}=9.9 \%,
\end{array}
$$

where it is understood that the reported coefficients are averages across all the monthly regressions. Second, we regressed the pricing errors of the B/M ratio model on the leverage ratio, and obtained:

$$
\begin{array}{lll}
\text { All-Bonds } & \left.\mathrm{APE}_{\ell}\right|_{\mathrm{B} / \mathrm{M}}=0.190+0.163 \mathrm{Lev}_{\ell}+\epsilon_{\ell}, & R^{2}=4.8 \%, \\
\text { BBB-Rated } & \left.\mathrm{APE}_{\ell}\right|_{\mathrm{B} / \mathrm{M}}=0.094+0.412 \mathrm{Lev}_{\ell}+\epsilon_{\ell}, & R^{2}=13.0 \% .
\end{array}
$$

In each of the regressions, we investigate whether the pricing errors are significantly correlated with an omitted firm-specific variable.

The results reinforce our earlier assertion that it may be possible to lower the pricing errors of BBB-rated bonds. For example, the leverage factor is positively and significantly related to the pricing errors of the $\mathrm{B} / \mathrm{M}$ ratio model. The average goodness-of-fit statistics from this regression is 
about $13.0 \%$. While $\mathrm{B} / \mathrm{M}$ is also positively related to the pricing errors of the leverage ratio model, the coefficient are much smaller. Although not done here, a credit risk model with two firm-specific variables may prove beneficial from a valuation perspective. Given data and space considerations, we leave a formal analysis of the four-factor credit risk models to a follow-up empirical project.

\section{$7 \quad$ Hedging Performance of Credit Risk Models}

We now proceed to examine the dynamic hedging performance of credit risk models. In the hedging strategy, as many instruments as sources of risks are employed to create a delta-neutral hedge in all dimensions. Four credit risk models are considered: (i) the leverage ratio model, (ii) the book-to-market ratio model, (iii) the stock price model, and (iv) the interest rate model. The first two credit risk models perform relatively better based on out-of-sample pricing, while the other two models rely on traded securities as factors.

To fix main ideas, suppose the target hedge is a short position in a corporate bond with $\tau$ periods to expiration and market price $\bar{P}(t, \tau)$. Take the stock price model for a benchmark illustration. In this model, there are three sources of uncertainty: the short interest rate, the long-term mean of the short interest rate and the issuing firm's stock. Therefore, the delta-neutral hedge employs three instruments: (i) a zero-coupon treasury with maturity $\tau_{1}$, (ii) another zerocoupon treasury with maturity $\tau_{2}$, and (iii) the issuing firm's stock. It is understood that the positioning in bonds neutralizes interest rate risk and the positioning in equity neutralizes equity risk. By a standard argument, the current value of the replicating portfolio is given by:

$$
w_{0}(t)+w_{1}(t) B\left(t, \tau_{1}\right)+w_{2}(t) B\left(t, \tau_{2}\right)+w_{3}(t) S(t)
$$

where $w_{1}(t), w_{2}(t)$ and $w_{3}(t)$, are the weights on the two treasury securities and the issuing firm's stock, respectively. Let the current stock price be denoted by $\mathrm{S}(\mathrm{t})$, and the yet undetermined residual cash position be $w_{0}(t)$. Using the fact that $d S(t)=r(t) S(t) d t+\sigma_{x} S(t) d \omega_{x}(t)$ and Ito's lemma, we arrive at the positioning below (see the Appendix for details):

$$
\begin{aligned}
w_{1}(t) & =\frac{\Delta_{z} \frac{\partial B\left(t, \tau_{2}\right)}{\partial r}-\Delta_{r} \frac{\partial B\left(t, \tau_{2}\right)}{\partial z}}{\frac{\partial B\left(t, \tau_{2}\right)}{\partial r} \frac{\partial B\left(t, \tau_{1}\right)}{\partial z}-\frac{\partial B\left(t, \tau_{2}\right)}{\partial z} \frac{\partial B\left(t, \tau_{1}\right)}{\partial r}}, \\
w_{2}(t) & =\frac{\Delta_{z} \frac{\partial B\left(t, \tau_{1}\right)}{\partial r}-\Delta_{r} \frac{\partial B\left(t, \tau_{1}\right)}{\partial z}}{\frac{\partial B\left(t, \tau_{1}\right)}{\partial r} \frac{\partial B\left(t, \tau_{2}\right)}{\partial z}-\frac{\partial B\left(t, \tau_{1}\right)}{\partial z} \frac{\partial B\left(t, \tau_{2}\right)}{\partial r}}, \quad \text { and }, \\
w_{3}(t) & =\frac{\Delta_{x}}{S(t)}
\end{aligned}
$$


The partial derivatives, $\frac{\partial B(t, \tau)}{\partial r}$ and $\frac{\partial B(t, \tau)}{\partial z}$, are in analytical closed-form using the bond valuation formula (14). To make the position self-financing at each date $t$, we impose the restriction that: $w_{0}(t)=\bar{P}(t, \tau)-w_{1}(t) B\left(t, \tau_{1}\right)-w_{2}(t) B\left(t, \tau_{2}\right)-w_{3}(t) S(t)$. The local risk exposures for the defaultable coupon bond are the aggregated face and coupon exposures as made exact below:

$$
\begin{aligned}
& \Delta_{r}(t, \tau) \equiv F \Delta_{r}^{*}(t, \tau)+\int_{0}^{\tau} c(t+u) \Delta_{r}^{*}(t, u) d u \\
& \Delta_{z}(t, \tau) \equiv F \Delta_{z}^{*}(t, \tau)+\int_{0}^{\tau} c(t+u) \Delta_{z}^{*}(t, u) d u
\end{aligned}
$$

and finally,

$$
\Delta_{x}(t, \tau) \equiv F \Delta_{x}^{*}(t, \tau)+\int_{0}^{\tau} c(t+u) \Delta_{x}^{*}(t, u) d u
$$

where $\Delta_{r}^{*}(t, \tau), \Delta_{z}^{*}(t, \tau)$ and $\Delta_{x}^{*}(t, \tau)$ are as displayed in $(21)$-(23). In sum, invoking the Markov property of the model, the positioning in the replicating portfolio (31) is a function of current market prices.

To study the hedging effectiveness of this model, we maintain a short position in the defaultable bond and construct the aforementioned hedge portfolio. We liquidate the combined position at time $t+\Delta t$ and compute the percentage hedging error as:

$$
\begin{aligned}
H(t+\Delta t)= & \frac{1}{\bar{P}(t, \tau)}\left\{w_{0}(t) \exp [r(t) \Delta t]+w_{1}(t) B\left(t+\Delta t, \tau_{1}-\Delta t\right)+w_{2} B\left(t+\Delta t, \tau_{2}-\Delta t\right)\right. \\
& \left.+w_{3}(t) S(t+\Delta t)-\bar{P}(t+\Delta t, \tau-\Delta t)\right\}
\end{aligned}
$$

where the term in the curly brackets represents the discrepancy between the replicating portfolio value and the value of the shorted target hedge. Therefore, under the stated convention, the cash position appreciates at the risk-free interest rate.

Rebalancing the replicating portfolio, we implement this hedging strategy each period and for each of the 93 individual firms. As a consequence, we have a cross-section of percentage hedging errors - one for each period $t$. The reported absolute percentage hedging error is given by: $\operatorname{AHE}(t+\Delta t) \equiv \frac{1}{K} \sum_{k=1}^{K}|H(t+\Delta t)|$, and the mean percentage hedging error is given by: $\operatorname{MHE}(t+\Delta t) \equiv \frac{1}{K} \sum_{k=1}^{K} H(t+\Delta t)$. Because the parameters of the credit risk models are updated once each quarter, the rebalancing frequency is set to three months and the hedging errors are calculated over the following one month (i.e., $\Delta t=1 / 12$ ).

Implementing a dynamic hedging strategy with the leverage ratio model (and the book-tomarket ratio model) poses a dilemma, as leverage (and book value) is non-traded. However, we use as instruments in constructing the hedge treasuries and individual equity price that hedges the 
market component of leverage and book-to-market. In particular, the long-term debt component of leverage is left unhedged over the next one-month period. That is, write leverage as Lev $(t)=$ $\frac{D(t) / q}{S(t)+D(t) / q}$, where $q$ is the number of shares outstanding and $D(t)$ is the debt value from the previous period (to avoid look-ahead biases). Proceeding in the same fashion as before, we can derive $w_{1}(t)$ and $w_{2}(t)$ as shown in $(32)-(33)$ and $w_{3}(t)=-\Delta_{x} \times \frac{D(t) / q}{(S(t)+D(t) / q)^{2}}$. Replace $\mathrm{D}(\mathrm{t})$ with $\mathrm{B}(\mathrm{t})$ to get the respective positioning for the book-to-market ratio model. The percentage hedging errors for the respective credit risk model can now be computed by appealing to equation (38).

Panel A of Table 10 presents the hedging error results. A number of points are worth highlighting. First, using equity of a firm as a hedging instrument reduces the model hedging errors. Specifically, measured by both the absolute (percentage) hedging errors and the mean hedging errors, the performance of the stock price model is relatively better than its competitors. To be concrete, the average absolute (mean) hedging error for the stock price model is $1.43 \%(0.57 \%)$. The corresponding hedging errors for the interest rate model is $1.54 \%(0.65 \%)$. That the use of equity positioning improves hedging effectiveness is also observed in subsamples. The same conclusion holds when we replace average hedging error with median errors (not reported). The finding that stock price model provides superior hedging performance is in contrast to the result that stock price model has the worst out-of-sample pricing performance. Therefore, we are potentially confronted with a situation where a credit risk model with the best dynamic hedging performance may in fact provide the worst out-of-sample performance. Simulations confirm that this is possible when the introduction of the non-traded explanatory variable hinders the working of the traded variables.

Second, leaving the debt component and the book component of leverage and book-to-market unaccounted in the delta-neutral strategy can impair the hedging ability of the credit risk models. Despite the use of equity as an instrument in these models, the absolute hedging errors from the leverage ratio model are sometimes even higher than that of the interest rate model (in 8 out 16 categories with $\mathrm{AHE}$ and 4 out of 16 with MHE). When averaged over all bonds, the absolute hedging error of the leverage ratio (book-to-market) model is $1.53 \%$ (1.61\%) compared to $1.54 \%$ for the interest rate model. One lesson inherent in this hedging exercise is that credit risk models relying on purely traded factor tend to produce better hedging effectiveness. Moreover, information about dynamic changes in the debt/book value of the firm is economically relevant for the profit/loss accounts of the hedger.

Third, for all credit risk models, the delta-neutral absolute hedging errors are consistently lower for short-term bonds. That is, higher the maturity of the bond, the more variable is the hedge, even after controlling for credit rating. The hedging errors are found to rise with maturity, but not as fast as maturity. The latter result is consistent with the out-of-sample pricing exercises 
where the absolute yield errors were relatively higher for short-term bonds. Shifting focus to the mean hedging errors, all the credit risk models over-hedge the target short position, regardless of the bond maturity. We can also make the observation that the MHE are hump-shaped, with medium-term bonds over-shooting its target position the most.

Fourth, the hedging performance is generally better for high quality borrowers than for less credit worthy borrowers. In this case, the relative ranking from the absolute hedging errors and mean hedging errors are in agreement. Each for short-term and medium-term bonds, the hedging errors are U-shaped in credit rating for each model: going down first from AA-rated to A-rated, and then rising to BBB-rated bonds. As stressed earlier, the average maturity of the AA bonds in our sample is much longer than that of the A bonds. This aspect of the bond data may explain the better hedging performance for the A-rated bonds relative to the AA-rated bonds.

Although not shown in a table, for all models, the hedging performance is the best for utility firms, while there is no clear pattern in the hedging performance between financial and industrial firms. This result also mirrors the out-of-sample pricing performance in the previous section.

When we split the sample period into two parts, the hedging errors are virtually similar. Our conclusions about hedging effectiveness are not a factor of the sample.

Finally, delta-neutral hedging errors for 25 individual firms are presented in Panel B of Table 10. One noteworthy aspect of this table is that all four models perform consistently across firms. All the four models generate relatively low hedging errors for the same group of firms, while producing high hedging errors for other groups of firms. Overall, the instruments do a fairly good job neutralizing firm level default risk.

\section{Concluding Remarks and Future Work}

Inspired by the strand of research in Duffee (1999), Duffie and Singleton (1997), Jarrow and Turnbull (1995), Longstaff and Schwartz (1995), and Madan and Unal (1998), this paper has developed a theoretical and empirical framework for analyzing variations in defaultable bond yields. The valuation methodology relies on a surprise stopping time approach and imposes the assumption that recovery is a fraction of the pre-default value of the defaultable debt (Duffie and Singleton (1999)). Specifically, the theoretical approach offers the versatility that the defaultable discount rate can be formulated as a function of firm-specific distress factors as well as systematic distress factors. Our empirical investigation posed two questions of broad economic interest:

1. When fitted to defaultable coupon bonds, which credit risk model provides superior out-ofsample pricing and hedging performance? 
2. What type of factors are important for explaining credit risk? Do systematic (or firmspecific) distress factors drive the price of default?

Our analysis of credit risk models is based on measurable yardsticks. First, the econometric framework verifies that such firm-specific factors as leverage and book-to-market account for crosssectional variations in corporate yields. Second, based on the in-sample and out-of-sample pricing error metrics, it is shown that interest rate considerations are of first-order prominence in explaining the pricing and hedging of corporate bonds. At the same time, the empirical examination leads to the conclusion that firm-specific distress factors are not redundant. Particularly parameterized credit risk models that incorporate leverage and book-to-market reduce yield errors for the majority of the firms. This portion of the inquiry suggest that model performance is better for (i) high grade bonds than for low grade bonds (of comparable maturity), and for (ii) long-maturity bonds than for short-maturity bonds (of comparable credit rating). Valuation errors are correlated with default premium; if one were to consider broadening the set of systematic default factors, the default premium would be a good modeling choice. Finally, the use of individual equity as an instrument is desirable from dynamic hedging standpoints. Credit risk models neutralizing equity risk mitigate delta-neutral hedging errors.

Since callability, putability and convertibility are commonly associated features of corporate coupon bonds, more modeling effort is needed to characterize optionality. The class of credit risk models proposed here can be used to understand why firms employ certain type of derivatives. Moreover, closed-form modeling and empirical testing of credit derivatives continues to be an issue relevant to practitioners. Using our assumptions about the defaultable discount rate, the existing set-up can be adapted to price option contracts that are default contingent.

Whether it is an embedded option or a complex credit derivative, its intrinsic value can be made to depend on both systematic distress factors and issuer-specific distress factors. In principle, the empirical work can be extended to the class of non-affine default risk models. The availability of speculative grade bonds can further enhance our comprehension of default. Even though intuitively appealing, one could relax the prevailing assumption about recovery in default. Much remains to be reconciled about default risk. 


\section{Appendix: Proof of Results}

\section{Proof of the Defaultable Coupon Bond Price in Equation (7)}

In Duffie and Singleton (1999), the recovery in default is: $y(t)=\lambda(t) P\left(t_{-}, \tau\right)$, which is an adapted proportion of the pre-default bond value. In this case,

$$
\begin{aligned}
P(t, \tau)= & E_{t}^{Q}\left\{\int_{t}^{t+\tau} \exp \left(-\int_{t}^{u}[r(s)+h(s)] d s\right) d C(u)++F \exp \left(-\int_{t}^{t+\tau}[r(s)+h(s)] d s\right)\right. \\
& \left.+\int_{t}^{t+\tau} h(u) \lambda(u) P\left(u_{\rightarrow} \tau\right) \exp \left(-\int_{t}^{u}[r(s)+h(s)] d s\right) d u\right\} .
\end{aligned}
$$

Now define the discounted gains process:

$$
\begin{aligned}
G(t) \equiv & \int_{0}^{t} \exp \left(-\int_{0}^{u}(r(s)+h(s)) d s\right) d C(u)+ \\
& \int_{0}^{t} h(u) \lambda(u) P\left(u_{\rightarrow} \tau\right) \exp \left(-\int_{0}^{u}(r(s)+h(s)) d s\right) d u \\
& +\exp \left(-\int_{0}^{t}(r(s)+h(s)) d s\right) P(t, \tau)
\end{aligned}
$$

which is a martingale (because it is the conditional expectation of a terminal random variable). It follows by an application of Ito's lemma that:

$$
0=E_{t}^{Q}[d P(t, \tau)]+\{c(t)+h(t) \lambda(t) P(t, \tau)-[r(t)+h(t)] P(t, \tau)\} d t
$$

or that

$$
0=E_{t}^{Q}[d P(t, \tau)]+\{c(t)+[r(t)+(1-\lambda(t)) h(t)] P(t, \tau)\} d t .
$$

This implies by Ito's Lemma once again that

$$
\begin{aligned}
L(t) \equiv & \int_{0}^{t} c(u) \exp \left(-\int_{0}^{u}[r(s)+h(s)(1-\lambda(s)] d s) d u+\right. \\
& \exp \left(-\int_{0}^{t}[r(s)+h(s)(1-\lambda(s)] d s) P(t, \tau)\right.
\end{aligned}
$$

is a $Q$ martingale. Equating $L(t)$ to the conditional expectation of $L(T)$ and using the terminal condition $P(0, t+\tau)=F$, we obtain the desired result. 


\section{Proof of Delta-Neutral Hedges in Equations (32)-(34)}

Suppose we use a combination of two default-free discount bonds and the equity of the firm to hedge the defaultable coupon bond. Consider a replicating portfolio of the type:

$$
V(t)=w_{0}(t)+w_{1}(t) B\left(t, \tau_{1}\right)+w_{2}(t) B\left(t, \tau_{2}\right)+w_{3}(t) S(t),
$$

where $B\left(t, \tau_{\ell}\right)$ is the default-free discount bond price with maturity $\tau_{\ell}$ and $S(t)$ represents the equity price. Then,

$$
\begin{aligned}
d V(t)-E_{t}^{Q}[d V(t)]= & w_{3}(t)(d S-E[d S]) \\
& +(d r-E[d r])\left\{w_{1}(t) \frac{\partial B\left(t, \tau_{1}\right)}{\partial r}+w_{2}(t) \frac{\partial B\left(t, \tau_{2}\right)}{\partial r}\right\} \\
& +(d z-E[d z])\left\{w_{1}(t) \frac{\partial B\left(t, \tau_{1}\right)}{\partial z}+w_{2}(t) \frac{\partial B\left(t, \tau_{2}\right)}{\partial z}\right\} .
\end{aligned}
$$

It is also true that:

$$
d P(t)-E[d P(t)]=\frac{\partial P(t, \tau)}{\partial S} \frac{1}{S}(d S-E[d S])+(d r-E[d r]) \frac{\partial P(t, \tau)}{\partial r}+(d z-E[d z]) \frac{\partial P(t, \tau)}{\partial z}
$$

Comparing (43) and (44) and solving a set of simultaneous equations prove the positioning (32)(34) displayed in the text. 


\section{References}

Briys, E., and F. de Varenne, 1997, "Valuing risky fixed rate debt: an extension," Journal of Financial and Quantitative Analysis, Vol. 32, No.2, 239-248.

Brown, S., and P. Dybvig, 1986, "The empirical implications of the Cox, Ingersoll, Ross theory of the term structure of interest rates," Journal of Finance 41, 616-628.

Buhler, W., M. Uhrig-Homburg, U. Walter, and T. Webber, 1999, “An empirical comparison of forward and spot rate models for valuing interest rate options," Journal of Finance 54, 269-305.

Chen, R., and L. Scott, 1993, "Maximum likelihood estimation for a multifactor equilibrium model of the term structure of interest rates," Journal of Fixed Income 3, 14-31.

Collin-Dufresne, P., and R. Goldstein, 1999, "Do credit spreads reflect stationary leverage? Reconciling structural and reduced-form frameworks," Journal of Finance (forthcoming).

Collin-Dufresne, P., and B. Solnik, 1999, "On the term structure of default premia in the swap and LIBOR markets," Journal of Finance (forthcoming).

Dai, Q., and K. Singleton, 2000, "Specification analysis of affine term structure models," Journal of Finance 55 (5), 1943-1978.

Duffee, G., 1998, “The relation between treasury yields and corporate bond yield spreads," Journal of Finance 53, 2225-2242.

Duffee, G., 1999, "Estimating the price of default risk," Review of Financial Studies 12, No.1, $197-226$.

Duffie, D., 1996, Dynamic Asset Pricing Theory, 2nd edition, Princeton University Press, Princeton, New Jersey.

Duffie, D., and K. Singleton, 1997, "An econometric model of the term structure of interest rate swap yields," Journal of Finance 52, No.4, 1287-1322.

Duffie, D., and K. Singleton, 1999, "Modeling term structures of default risky bonds," Review of Financial Studies 12, No.4, 687-720.

Elton, E., M. Gruber, D. Agrawal, and C. Mann, 2001, "Explaining the rate spread on corporate bonds," Journal of Finance 56, No. 1, 247-277.

Eom, Y., J. Helwege, and J. Huang, 2000, "Structural models of corporate bond pricing: An empirical analysis," mimeo, Pennsylvania State University. 
Fama, E. and K. French, 1992, "The cross-section of expected stock returns," Journal of Finance 47, No.2, 427-465.

Gupta, A., and M. Subrahmanyam, 2000, "An estimation of the static and dynamic performance of interest rate option pricing models in the dollar cap-floor markets," mimeo, Case Western University and New York University.

Jarrow, R., D. Lando, and S. Turnbull, 1997, "A Markov model for the term structure of credit risk spreads," Review of Financial Studies 10, 481-523.

Jarrow, R., and S. Turnbull, 1995, "Pricing derivatives on financial securities subject to credit risk," Journal of Finance 50, 53-85.

Jones, E., S. Mason, and E. Rosenfeld, 1984, "Contingent claims analysis of corporate capital structures: An empirical investigation," Journal of Finance, 611-625.

Lando, David, 1998, “On Cox Processes and Credit Risky Securities," Review of Derivatives Research 2,99-120.

Litterman, R. and J. Scheinkman, 1991, "Common factors affecting bond returns," Journal of Fixed Income 1, 54-61.

Longstaff, F., and E. Schwartz, 1992, "Interest rate volatility and the term structure: A two-factor general equilibrium model," Journal of Finance 47, 1259-1282.

Longstaff, F., and E. Schwartz, 1995, “A simple approach to valuing risky fixed and floating rate debt," Journal of Finance 50, 789-819.

Madan, D., and H. Unal, 1998, "Pricing the risks of default," Review of Derivatives Research 2, 121-160.

Madan, D., and H. Unal, 2000, "Pricing risky debt: a two-factor hazard-rate model with complex capital structure," Journal of Financial and Quantitative Analysis 35, No. 1, 43-65.

Merton, R., 1974, "On the pricing of corporate debt: the risk structure of interest rates," Journal of Finance 29, 449-470.

Schwartz, T., 1998, "Estimating the Term Structures of Corporate Debt," Review of Derivatives Research 2,193-230.

Shumway, Tyler, 2001, "Forecasting bankruptcy more accurately: A simple hazard rate model," Journal of Business 74, No. 1, 101-124. 
Titman, S., and R. Wessels, 1988, "The determinants of capital structure choice," Journal of Finance, Vol.43, No.1, 1-19.

Vasicek, O., 1977, “An equilibrium characterization of the term structure," The Journal of $F i$ nancial Economics 5, 177-188.

Wei, D., and D. Guo, 1997, "Pricing risky debt: An empirical comparison of the Longstaff and Schwartz and Merton models," Journal of Fixed Income, September, 8-28. 
Table 1: Yield, Credit Rating and Firm-Specific Distress Factors

In this table, we report the following bond attributes: (i) the average number of bonds outstanding per month, (ii) the average yield (in \%), (iii) the average numerical credit rating (assigned by S\&P), and (iv) the average maturity. The source is Lehman Brothers Fixed Income Database. Leverage is long-term debt divided by firm value (sum of longterm debt and market value of equity); $\mathbf{B} / \mathbf{M}$ is book value of equity divided by the market value of equity; Profit is operating income divided by net sales. All accounting (equity price) information is taken from COMPUSTAT (CRSP). Bonds with credit rating between 1 and 5 are designated as AA-rated; between 6 to 8 as A-rated; and higher than 9 as BBB-rated (or below). Each of the 93 firms in our sample are coupon-paying, non-callable and non-putable. We classify firm-specific data by their industry affiliation, i.e., financial, industrial and utility. For brevity, only the information on 25 firms is shown. The number of observations is 46,262 . The sample period is March 1989 through March 1998.

\begin{tabular}{|c|c|c|c|c|c|c|c|}
\hline \multirow[b]{2}{*}{ Name } & \multicolumn{4}{|c|}{ Bond Attributes } & \multicolumn{3}{|c|}{ Distress Factors } \\
\hline & $\begin{array}{l}\text { No. of } \\
\text { Bonds }\end{array}$ & Yield & $\begin{array}{l}\text { Credit } \\
\text { Rating }\end{array}$ & Maturity & Leverage & $\mathrm{B} / \mathrm{M}$ & Profit \\
\hline Amr Corp & 11.1 & 8.24 & 11.1 & 15.4 & 0.530 & 0.739 & 0.132 \\
\hline Boeing Company & 7.8 & 7.39 & 3.9 & 29.7 & 0.119 & 0.504 & 0.090 \\
\hline Bank of America & 17.7 & 7.18 & 7.4 & 6.9 & 0.337 & 0.531 & 0.268 \\
\hline Bell South Corp & 7.5 & 6.84 & 2.0 & 22.4 & 0.167 & 0.355 & 0.444 \\
\hline Bear Stearns Co. & 10.7 & 6.97 & 7.1 & 6.0 & 0.613 & 0.710 & 0.568 \\
\hline Bankers Trust NY & 12.2 & 7.00 & 6.4 & 6.6 & 0.541 & 0.679 & 0.087 \\
\hline Citicorp & 11.5 & 7.66 & 6.8 & 5.7 & 0.535 & 0.831 & 0.199 \\
\hline Coastal Corp & 8.7 & 7.43 & 11.7 & 11.2 & 0.483 & 0.684 & 0.105 \\
\hline Chase Manhatten & 9.2 & 8.32 & 8.4 & 6.1 & 0.588 & 1.570 & 0.161 \\
\hline Csx Corp & 6.8 & 7.26 & 9.7 & 11.6 & 0.302 & 0.503 & 0.185 \\
\hline Delta Airlines & 7.9 & 8.65 & 11.5 & 15.5 & 0.440 & 0.627 & 0.079 \\
\hline Consolidated Edison & 8.4 & 6.64 & 5.8 & 5.6 & 0.356 & 0.748 & 0.278 \\
\hline Edison Internaitonal & 10.1 & 6.59 & 6.1 & 4.3 & 0.448 & 0.742 & 0.352 \\
\hline Enron Corp & 8.0 & 7.37 & 9.8 & 8.3 & 0.337 & 0.396 & 0.110 \\
\hline Ford Motor Company & 7.5 & 7.29 & 6.5 & 19.9 & 0.771 & 0.737 & 0.192 \\
\hline First Chicago NBD & 9.0 & 7.88 & 7.9 & 7.2 & 0.433 & 1.052 & 0.215 \\
\hline First Union Corp & 9.9 & 6.91 & 8.1 & 7.1 & 0.309 & 0.639 & 0.230 \\
\hline IBM & 6.2 & 7.04 & 7.0 & 20.1 & 0.182 & 0.388 & 0.157 \\
\hline International Paper & 7.2 & 7.14 & 8.0 & 9.2 & 0.331 & 0.728 & 0.136 \\
\hline Merrill Lynch \& Co. & 17.6 & 6.73 & 5.9 & 5.1 & 0.621 & 0.710 & 0.514 \\
\hline Philip Morris Co. & 18.4 & 6.91 & 7.0 & 5.4 & 0.190 & 0.206 & 0.228 \\
\hline Usx Corp & 8.7 & 7.90 & 11.6 & 14.7 & 0.446 & 0.757 & 0.112 \\
\hline Niagara Mohawk Hld. & 7.3 & 8.00 & 11.6 & 7.5 & 0.641 & 1.422 & 0.233 \\
\hline Time Warner, Inc & 7.7 & 7.67 & 11.0 & 13.7 & 0.386 & 0.241 & 0.166 \\
\hline Wal-Mart Stores Inc & 11.2 & 6.71 & 4.0 & 8.5 & 0.132 & 0.226 & 0.060 \\
\hline All & 46262 & 7.26 & 7.7 & 9.43 & 0.427 & 0.635 & 0.229 \\
\hline Utility & 10336 & 7.08 & 8.4 & 8.14 & 0.443 & 0.755 & 0.314 \\
\hline Financial & 15452 & 7.22 & 6.9 & 6.80 & 0.546 & 0.738 & 0.264 \\
\hline Industrial & 20474 & 7.39 & 8.2 & 12.12 & 0.341 & 0.496 & 0.163 \\
\hline $\mathrm{AA}$ & 7081 & 7.07 & 4.3 & 11.32 & 0.334 & 0.534 & 0.166 \\
\hline A & 24410 & 7.08 & 7.1 & 8.58 & 0.432 & 0.622 & 0.265 \\
\hline BBB and below & 14771 & 7.65 & 10.6 & 9.89 & 0.477 & 0.710 & 0.209 \\
\hline
\end{tabular}


Table 9: Analysis of Credit Rating and Maturity Related Biases

The regression results are based on the following time-series specification: $\operatorname{APE}(t)=\eta_{0}+\eta_{g} \operatorname{GIP}(t)+\eta_{p} \operatorname{TERM}(t)+$ $\eta_{d} \operatorname{DEF}(t)+\epsilon(t)$. GIP is the growth rate of industrial production, TERM, the term premium, is the yield difference between the 30 year treasury bond rate and the 3 -month treasury bill rate, and DEF, the default premium, is the yield difference between BBB-rated corporate bonds and AAA-rated corporate bonds. The method of estimation is OLS. The t-statistic is computed using a heteroskedasically consistent estimator. $R^{2}$ is the adjusted- $R^{2}$ statistic (in \%). The regressions are done by rating and maturity. The sample period is March 1989 through March 1998. APE is the out-of-sample absolute percentage pricing errors aggregated across the respective category.

\begin{tabular}{|c|c|c|c|c|c|c|c|c|c|c|}
\hline & & $\eta_{0}$ & $\mathrm{t}\left(\eta_{0}\right)$ & $\eta_{g}$ & $\mathrm{t}\left(\eta_{g}\right)$ & $\eta_{p}$ & $\mathrm{t}\left(\eta_{p}\right)$ & $\eta_{d}$ & $\mathrm{t}\left(\eta_{d}\right)$ & $R^{2}$ \\
\hline \multirow{6}{*}{ AA } & Leverage & 0.016 & 3.74 & 0.004 & 2.15 & 0.001 & 1.25 & -0.007 & -1.33 & 10.5 \\
\hline & $\mathrm{B} / \mathrm{M}$ & 0.017 & 3.92 & 0.004 & 2.11 & 0.001 & 0.91 & -0.007 & -1.43 & 9.9 \\
\hline & Profitability & 0.038 & 5.55 & 0.002 & 0.63 & 0.001 & 1.38 & -0.026 & -3.34 & 14.5 \\
\hline & Lagged Spread & 0.021 & 4.95 & 0.004 & 2.24 & 0.000 & 0.56 & -0.011 & -2.34 & 15.4 \\
\hline & Stock Price & 0.024 & 5.36 & -0.000 & -0.16 & 0.001 & 1.62 & -0.012 & -2.27 & 6.1 \\
\hline & Interest Rate & 0.020 & 4.79 & 0.004 & 2.18 & 0.000 & 0.46 & -0.010 & -2.02 & 12.8 \\
\hline \multirow{6}{*}{ A } & Leverage & 0.002 & 0.65 & 0.003 & 1.82 & 0.001 & 1.42 & 0.010 & 2.54 & 6.3 \\
\hline & $\mathrm{B} / \mathrm{M}$ & 0.002 & 1.65 & 0.003 & 1.43 & 0.001 & 2.53 & 0.010 & 2.53 & 6.1 \\
\hline & Profitability & 0.027 & 5.75 & 0.003 & 1.42 & 0.004 & 5.59 & -0.006 & -1.12 & 27.6 \\
\hline & Lagged Spread & 0.003 & 0.82 & 0.003 & 1.69 & 0.001 & 1.35 & 0.010 & 2.47 & 5.7 \\
\hline & Stock Price & 0.002 & 0.47 & -0.002 & -1.02 & 0.001 & 1.41 & 0.019 & 3.64 & 17.5 \\
\hline & Interest Rate & 0.002 & 0.51 & 0.003 & 1.98 & 0.001 & 0.92 & 0.012 & 2.86 & 6.6 \\
\hline \multirow{6}{*}{ BBB } & Leverage & 0.004 & 1.06 & 0.002 & 1.50 & 0.001 & 1.28 & 0.015 & 3.45 & 9.9 \\
\hline & $\mathrm{B} / \mathrm{M}$ & 0.006 & 1.80 & 0.002 & 1.21 & 0.001 & 1.48 & 0.012 & 2.89 & 7.4 \\
\hline & Profitability & 0.046 & 7.62 & 0.003 & 1.29 & 0.001 & 1.36 & -0.019 & -2.71 & 13.6 \\
\hline & Lagged Spread & 0.004 & 0.99 & 0.003 & 1.64 & 0.001 & 1.23 & 0.015 & 3.43 & 9.7 \\
\hline & Stock Price & 0.009 & 2.35 & 0.003 & 1.66 & 0.001 & 1.22 & 0.014 & 3.10 & 7.9 \\
\hline & Interest Rate & 0.007 & 2.00 & 0.002 & 0.99 & 0.001 & 2.41 & 0.008 & 1.83 & 6.5 \\
\hline \multirow{6}{*}{ Short } & Leverage & 0.001 & 0.44 & 0.002 & 2.29 & 0.001 & 3.57 & 0.006 & 3.24 & 19.1 \\
\hline & $\mathrm{B} / \mathrm{M}$ & 0.001 & 0.80 & 0.001 & 2.18 & 0.001 & 3.45 & 0.005 & 2.87 & 17.1 \\
\hline & Profitability & 0.020 & 7.25 & 0.002 & 1.53 & 0.002 & 3.70 & -0.008 & -2.50 & 22.7 \\
\hline & Lagged Spread & 0.001 & 0.42 & 0.002 & 2.31 & 0.001 & 3.51 & 0.006 & 3.21 & 18.8 \\
\hline & Stock Price & 0.001 & 0.17 & -0.002 & -1.40 & 0.001 & 1.81 & 0.012 & 3.53 & 19.2 \\
\hline & Interest Rate & 0.001 & 0.51 & 0.002 & 2.47 & 0.001 & 3.21 & 0.006 & 3.17 & 17.5 \\
\hline \multirow{6}{*}{ Medium } & Leverage & -0.012 & -2.30 & 0.003 & 1.34 & -0.000 & -0.07 & 0.035 & 6.01 & 26.1 \\
\hline & $\mathrm{B} / \mathrm{M}$ & -0.010 & -2.03 & 0.002 & 1.09 & -0.000 & -0.15 & 0.033 & 5.77 & 24.8 \\
\hline & Profitability & -0.027 & 4.24 & 0.004 & 1.59 & 0.002 & 2.15 & 0.006 & 0.83 & 5.3 \\
\hline & Lagged Spread & 0.011 & -2.19 & 0.003 & 1.37 & -0.000 & -0.18 & 0.034 & 6.06 & 26.3 \\
\hline & Stock Price & -0.008 & -1.83 & -0.001 & -0.57 & 0.000 & 0.24 & 0.039 & 7.51 & 42.7 \\
\hline & Interest Rate & -0.009 & -1.95 & 0.003 & 1.31 & 0.000 & 0.08 & 0.032 & 5.70 & 23.8 \\
\hline \multirow{6}{*}{ Long } & Leverage & 0.018 & 2.95 & 0.005 & 1.89 & 0.001 & 1.11 & 0.001 & 0.10 & 3.6 \\
\hline & $\mathrm{B} / \mathrm{M}$ & 0.018 & 2.92 & 0.005 & 1.69 & 0.001 & 1.16 & 0.001 & 0.14 & 2.7 \\
\hline & Profitability & 0.046 & 6.13 & 0.003 & 0.89 & 0.001 & 1.12 & -0.005 & -0.55 & 1.0 \\
\hline & Lagged Spread & 0.020 & 3.18 & 0.005 & 1.70 & 0.001 & 0.93 & -0.000 & -0.01 & 2.4 \\
\hline & Stock Price & 0.029 & 4.90 & 0.003 & 1.33 & 0.001 & 1.54 & -0.006 & -0.85 & 4.8 \\
\hline & Interest Rate & 0.020 & 3.09 & 0.006 & 1.93 & -0.001 & -0.59 & 0.006 & 0.80 & 0.8 \\
\hline
\end{tabular}




\begin{tabular}{|c|c|c|c|c|c|c|c|}
\hline 毒 & : & 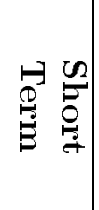 & 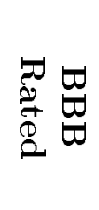 & 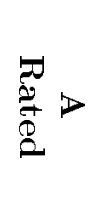 & 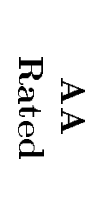 & & 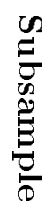 \\
\hline$\vec{E}$ & $\vec{N}$ & $\overrightarrow{\vec{c}}$ & $\vec{\infty}$ & 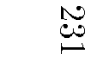 & 8 & & $E$ \\
\hline 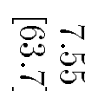 & $\begin{array}{l}\vec{P} \\
\infty \\
0 \\
0\end{array}$ & 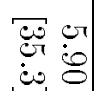 & 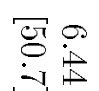 & $\begin{array}{l}\vec{B} \\
-10 \\
0\end{array}$ & $\begin{array}{l}\vec{\theta} \\
\overrightarrow{0} \\
\dot{0}\end{array}$ & $\bar{\sigma}$ & \\
\hline $\begin{array}{l}\sigma \stackrel{\circ}{\circ} \\
\dot{0}\end{array}$ & $\begin{array}{l}\vec{P} \\
\dot{0} 8\end{array}$ & $\begin{array}{ll}\vec{F} & 0 \\
0 & 0 \\
\oplus & 0\end{array}$ & 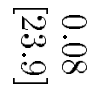 & 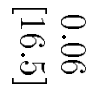 & 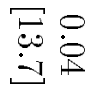 & $\Xi$ & $\frac{5}{D}$ \\
\hline $\begin{array}{l}\vec{\infty} \\
\infty \\
\infty \\
\infty\end{array}$ & 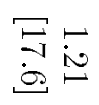 & 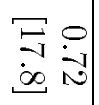 & 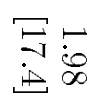 & $\begin{array}{l}P \\
\oplus \underset{ن}{0}\end{array}$ & 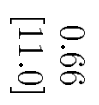 & $\overrightarrow{0}$ & $\begin{array}{l}-1 \\
0 \\
0 \\
0\end{array}$ \\
\hline $\begin{array}{l}\overrightarrow{\vec{c}} \\
\dot{\vec{c}} \\
\dot{\theta}\end{array}$ & $\begin{array}{l}\vec{\sigma} \\
\vec{\sigma} \\
\stackrel{\sigma}{0}\end{array}$ & 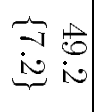 & 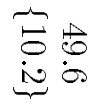 & $\underbrace{\vec{c}}_{\sim} \underset{\infty}{\overrightarrow{+}}$ & $\begin{array}{ll}\vec{y} & \overrightarrow{1} \\
0 & -1\end{array}$ & $\mathcal{J}_{\mathrm{J}}^{\mathrm{J}}$ & 0 \\
\hline $\begin{array}{l}\infty \\
\stackrel{1}{1} \\
\perp\end{array}$ & $\underset{\infty}{8}$ & $\begin{array}{l}8 \\
\infty \\
\infty\end{array}$ & $\begin{array}{l}\infty \\
-1 \\
-1\end{array}$ & $\stackrel{\bullet}{\bullet}$ & $\begin{array}{l}\vec{\infty} \\
\infty\end{array}$ & $\overrightarrow{\vec{v}}$ & \\
\hline $\begin{array}{ll}\vec{T} & -1 \\
0 & -1 \\
0,0 & 0\end{array}$ & $\begin{array}{l}\vec{B} \\
\overrightarrow{0} \\
\dot{0}=0\end{array}$ & 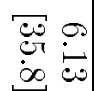 & 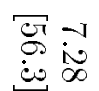 & $\begin{array}{l}\vec{D} \\
\infty \\
\infty \\
\infty \\
\infty\end{array}$ & 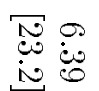 & $\exists$ & \\
\hline $\begin{array}{l}c, \\
\infty \\
\infty\end{array}$ & 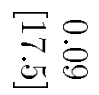 & $\begin{array}{ll}\vec{F} & 0 \\
\infty & 0 \\
\infty & 0\end{array}$ & 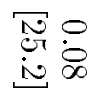 & $\begin{array}{l}\vec{\sigma} \\
\dot{0} \\
\dot{0}\end{array}$ & $\begin{array}{l}\vec{P} \\
\dot{0} \\
\dot{0}\end{array}$ & $\exists$ & $\vec{\Xi}$ \\
\hline 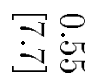 & $\begin{array}{l}0 \\
0 \\
0\end{array}$ & 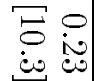 & 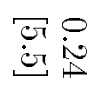 & $\vec{~}$ & $\begin{array}{l}\overrightarrow{0} \\
\dot{e}\end{array}$ & 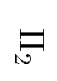 & $\ddot{\sigma}$ \\
\hline 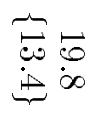 & $\underbrace{\vec{P}}_{\vec{D}}$ & 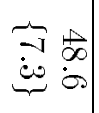 & $\underset{\underbrace{}}{\vec{\theta}}$ & 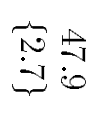 & $\begin{array}{l}\vec{\infty}: \overrightarrow{0} \\
\stackrel{0}{=}\end{array}$ & $\mathcal{D}_{0}$ & . \\
\hline$\stackrel{t}{0}$ & $\begin{array}{l}-1 \\
\dot{D}\end{array}$ & $\begin{array}{c}8 \\
0 \\
-1\end{array}$ & $\begin{array}{l}\text { gr } \\
\text { cr }\end{array}$ & $\stackrel{\oplus}{\stackrel{c}{\rightleftarrows}}$ & $\begin{array}{l}8 \\
\dot{0} \\
\dot{c}\end{array}$ & $\overrightarrow{\vec{v}}$ & \\
\hline $\begin{array}{l}\sigma_{0}^{\infty} \\
\dot{0} \\
\infty \\
\infty\end{array}$ & 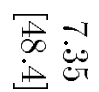 & 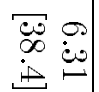 & $\begin{array}{ll}\vec{c} & -1 \\
0 & -1 \\
-1 & 0\end{array}$ & $\begin{array}{l}\vec{b} \\
\overrightarrow{0} \\
-1\end{array}$ & $\begin{array}{l}\vec{S} \\
\dot{\theta} \\
\dot{\theta}\end{array}$ & $\bar{\sigma}$ & \\
\hline 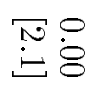 & $\begin{array}{l}\overrightarrow{0} \dot{0} \\
\dot{0}\end{array}$ & $\begin{array}{ll}\vec{\sigma} & 0 \\
\dot{0} & 0 \\
\dot{0} & \infty\end{array}$ & $\begin{array}{l}\mathbb{N} \\
\stackrel{0}{\infty} \\
\dot{\infty}\end{array}$ & $\begin{array}{l}\vec{P} \\
\dot{0} \\
\dot{\theta}\end{array}$ & $\begin{array}{l}\overrightarrow{0} \\
\dot{0} \\
\dot{\infty}\end{array}$ & $\Xi$ & ثี \\
\hline 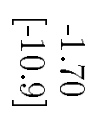 & 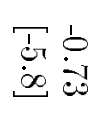 & $\begin{array}{ll}T & \dot{0} \\
\stackrel{5}{0} & \stackrel{0}{\oplus}\end{array}$ & 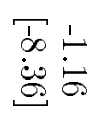 & 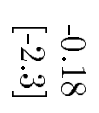 & 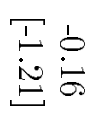 & $\vec{\omega}$ & $\begin{array}{l}.0 \\
ت \sigma 0 \\
0\end{array}$ \\
\hline 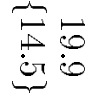 & $\begin{array}{l}\stackrel{\leftrightarrow}{\dot{\omega}} \rightleftarrows \\
\stackrel{\infty}{\oplus}\end{array}$ & 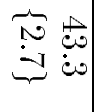 & $\underbrace{\vec{b}_{0}^{\infty}}_{-1}$ & 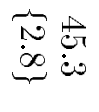 & $\begin{array}{l}\vec{v} \\
\vec{v} \\
\overrightarrow{\mid c}\end{array}$ & $\mathcal{J ్}_{\mathcal{N}}$ & : \\
\hline $\begin{array}{l}\stackrel{e}{\sigma} \\
\text { ci }\end{array}$ & $\begin{array}{l}0 \\
0 \\
\infty\end{array}$ & | & $\begin{array}{l}\vec{\infty} \\
0 \\
0\end{array}$ & مَ & $\begin{array}{l}\vec{\sigma} \\
\dot{\mathrm{c}}\end{array}$ & $\overrightarrow{\hat{\imath}}$ & \\
\hline
\end{tabular}

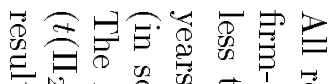

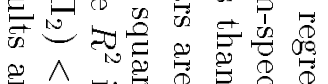

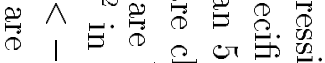

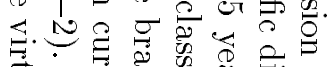

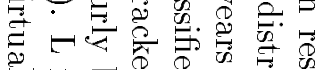

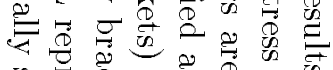

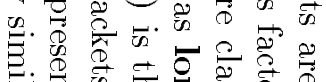

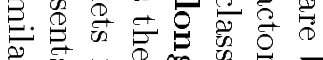

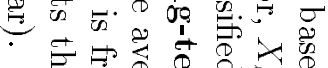
$\overrightarrow{0} \nabla 00$ $\exists \exists$ के के

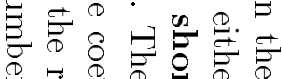

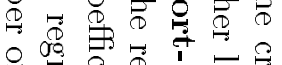

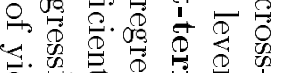

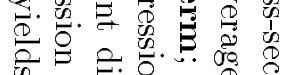

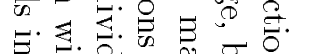

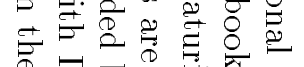

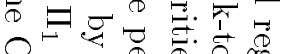
思 III

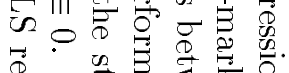
要

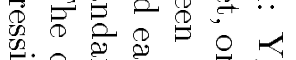

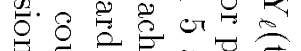

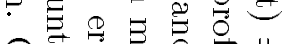

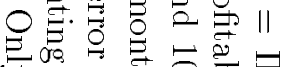

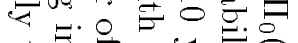

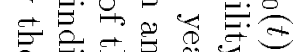
$\Rightarrow$ 远施

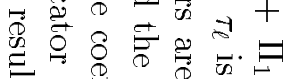

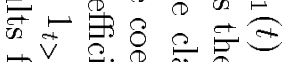

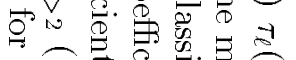

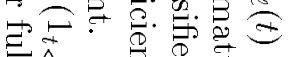
可

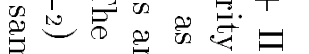

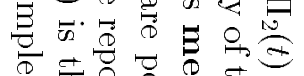

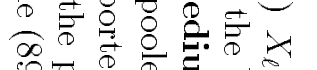

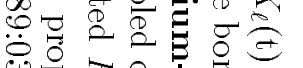
ن

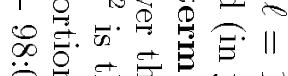

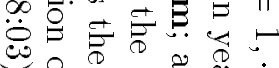

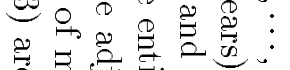

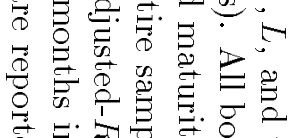

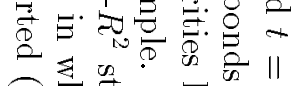

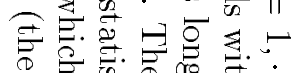

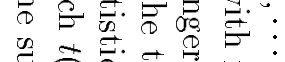

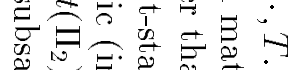

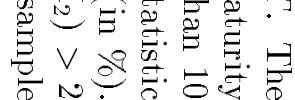

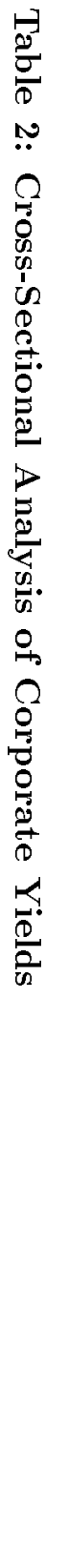




\begin{tabular}{|c|c|c|c|c|}
\hline 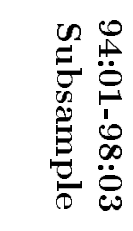 & 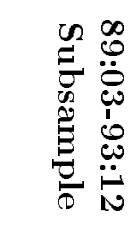 & $\underbrace{\infty}_{0}$ & & \multirow{11}{*}{ 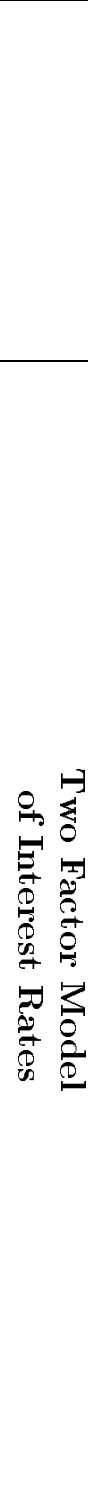 } \\
\hline 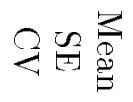 & 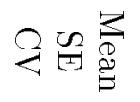 & 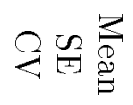 & & \\
\hline $\begin{array}{lll}0 & 0 \\
0 & 0 & 0 \\
0 & 0 & 0 \\
0 & 0 & 0\end{array}$ & 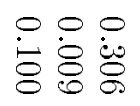 & 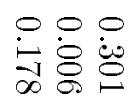 & $t^{2}$ & \\
\hline 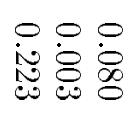 & 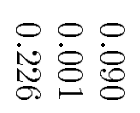 & 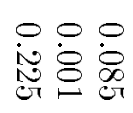 & $N$ & \\
\hline 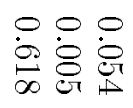 & 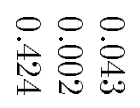 & $\begin{array}{l}\circ \\
.\end{array}$ & 9 & \\
\hline 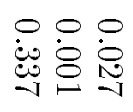 & 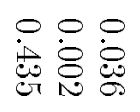 & 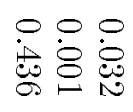 & टरे & \\
\hline 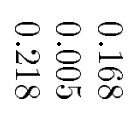 & 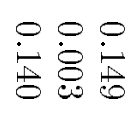 & 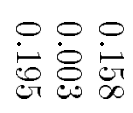 & $\bar{z}$ & \\
\hline 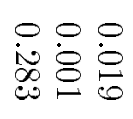 & 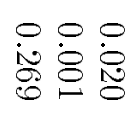 & 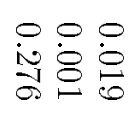 & 9 & \\
\hline 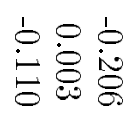 & 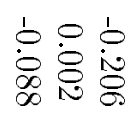 & 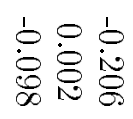 & $P$ & \\
\hline 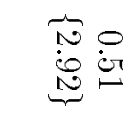 & 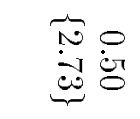 & $\begin{array}{ll}\hat{n} & 0 \\
0 & 0 \\
0 & 0\end{array}$ & S2 & \\
\hline 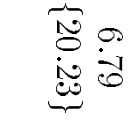 & 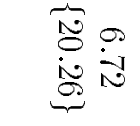 & 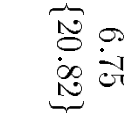 & 를 & \\
\hline $\begin{array}{l}0 \\
0\end{array}$ & 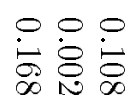 & 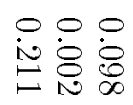 & $N$ & \multirow{5}{*}{ 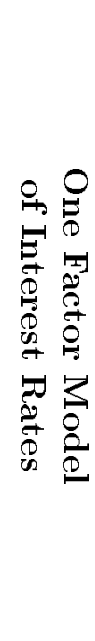 } \\
\hline 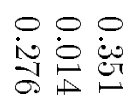 & 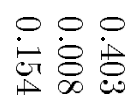 & 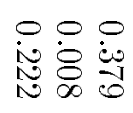 & స్త్ర & \\
\hline 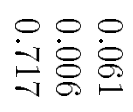 & 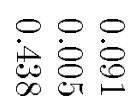 & 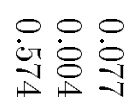 & 9 & \\
\hline$\underbrace{\underbrace{}_{0}}$ & 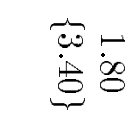 & $\underbrace{-\underbrace{}_{0}}$ & (2) & \\
\hline 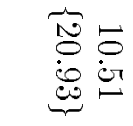 & 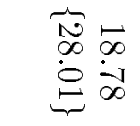 & 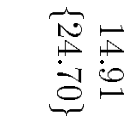 & 할 & \\
\hline
\end{tabular}

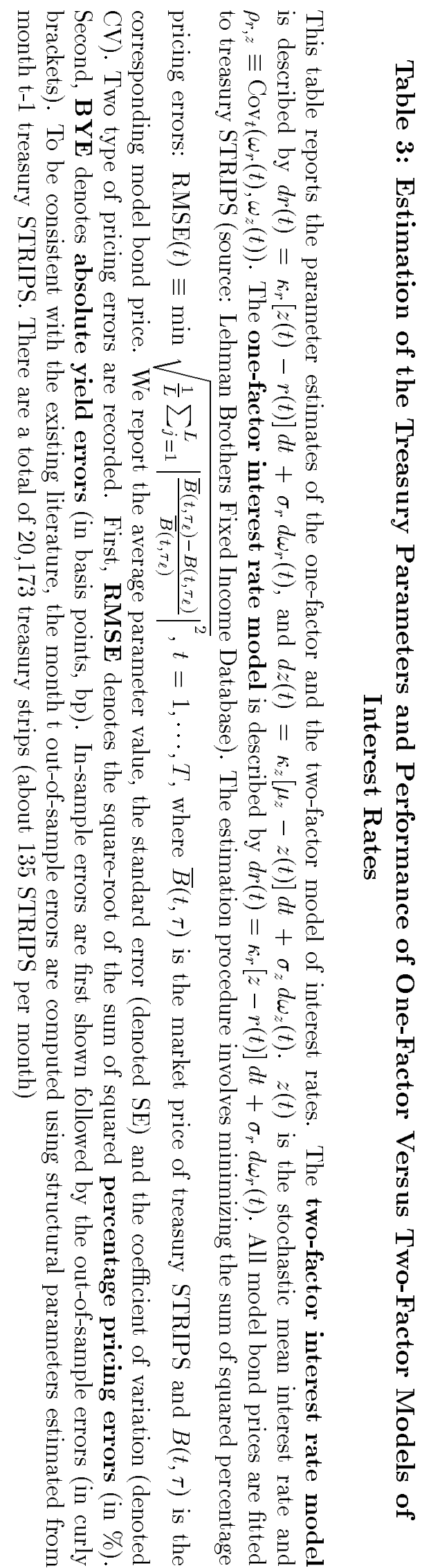




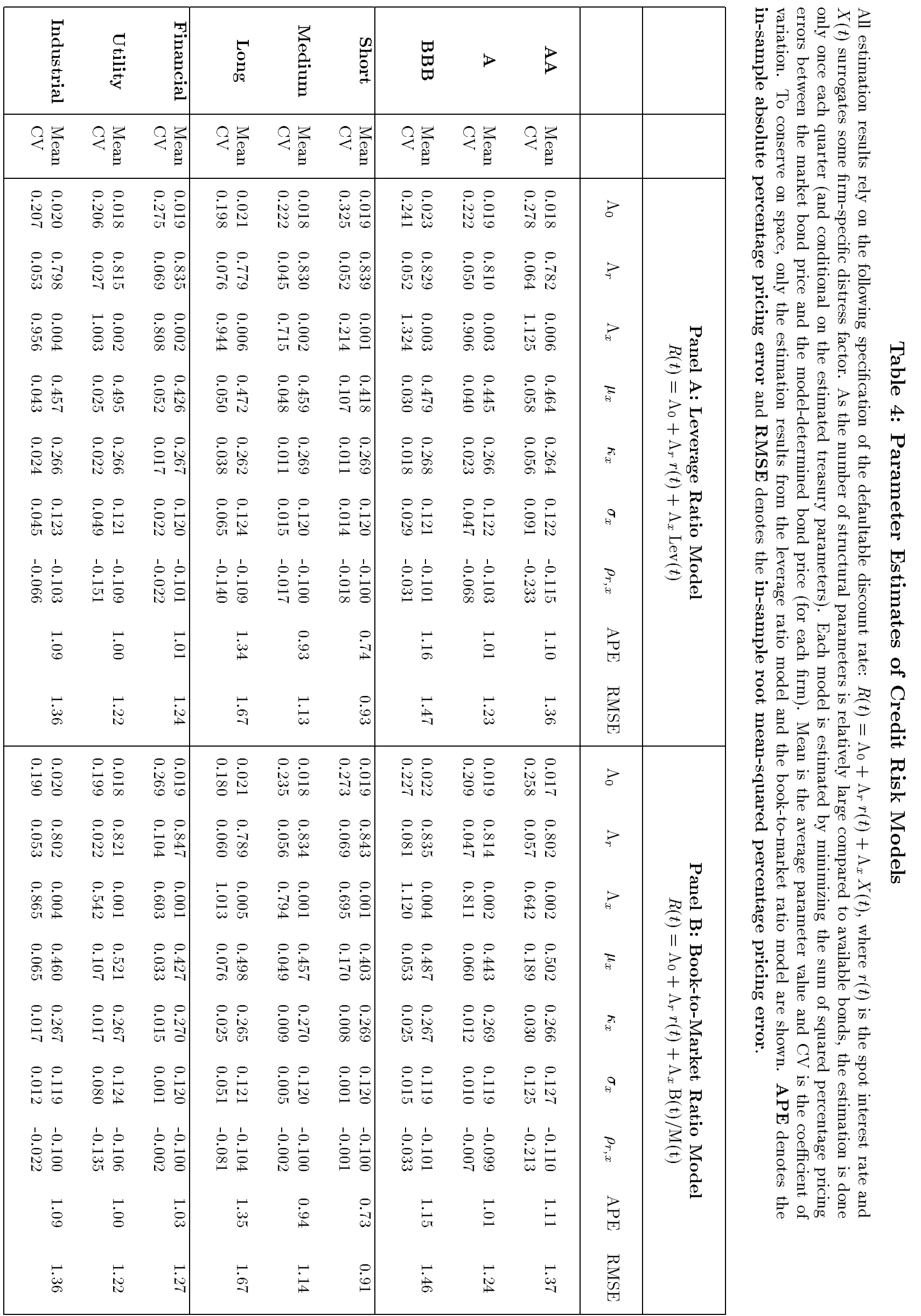




\begin{tabular}{|c|c|c|c|c|}
\hline 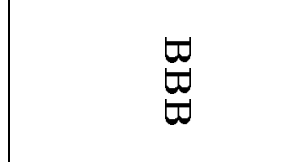 & $D$ & $\vec{D}$ & $\stackrel{\mathbb{D}}{=}$ & 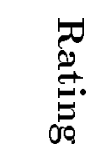 \\
\hline 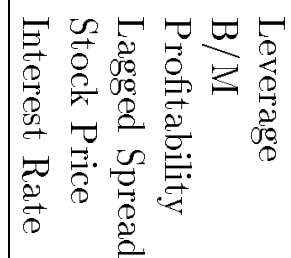 & 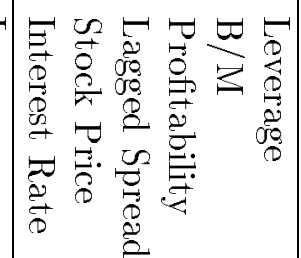 & 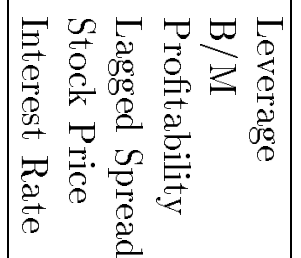 & 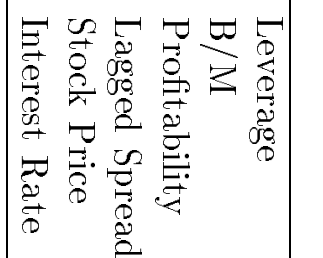 & $\begin{array}{l}3 \\
0 \\
0 \\
0\end{array}$ \\
\hline 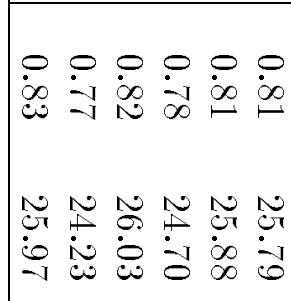 & 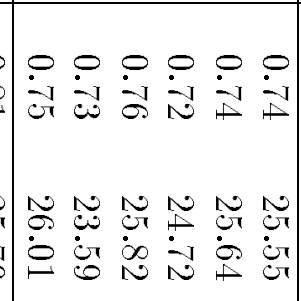 & 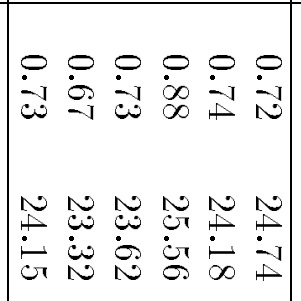 & | & 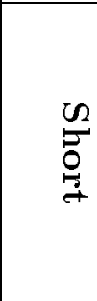 \\
\hline 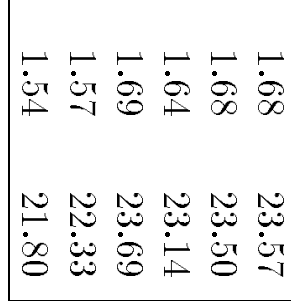 & 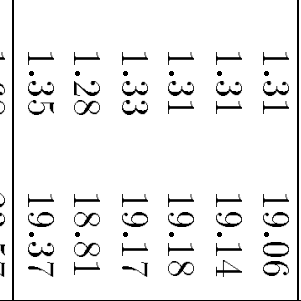 & 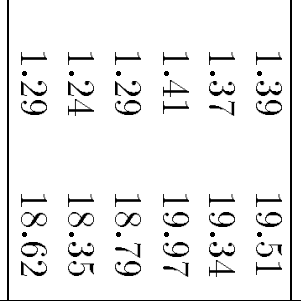 & 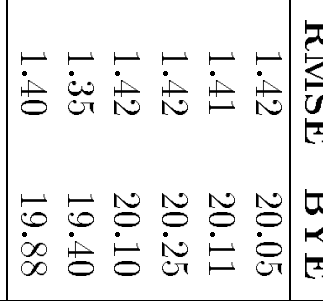 & 客 \\
\hline 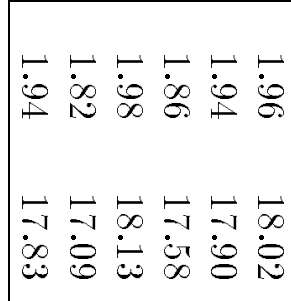 & 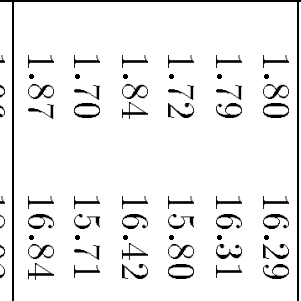 & 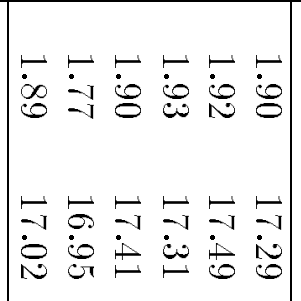 & 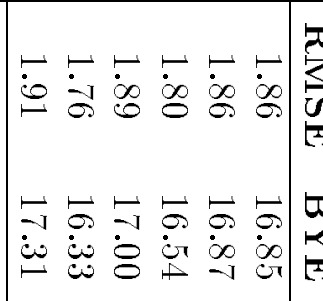 & $\stackrel{\vec{\circ}}{\stackrel{5}{\circ}}$ \\
\hline 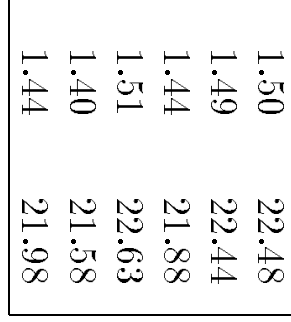 & 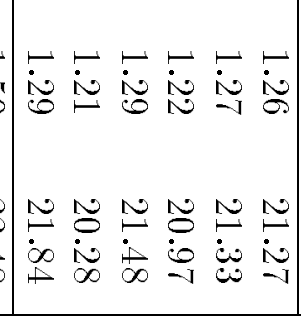 & 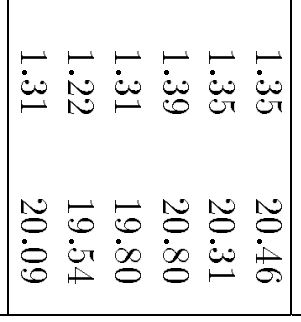 & 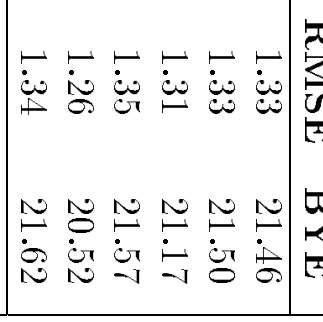 & $\stackrel{\bullet}{=}$ \\
\hline
\end{tabular}




\begin{tabular}{|c|c|c|c|c|c|}
\hline & $D$ & $\frac{D}{D}$ & $\stackrel{D}{=}$ & & 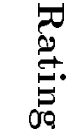 \\
\hline 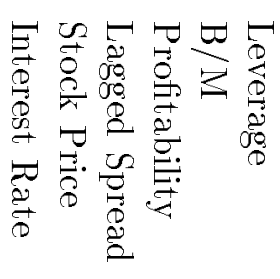 & 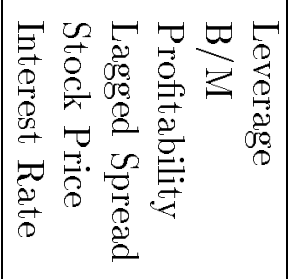 & 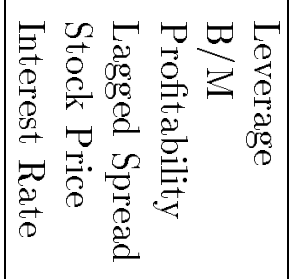 & 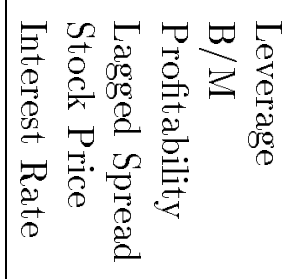 & & $\begin{array}{l}3 \\
3 \\
0 \\
0 \\
0\end{array}$ \\
\hline 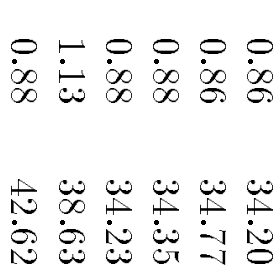 & 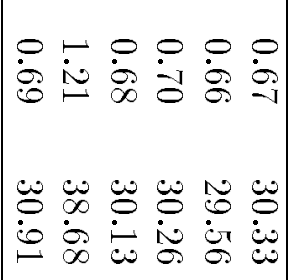 & 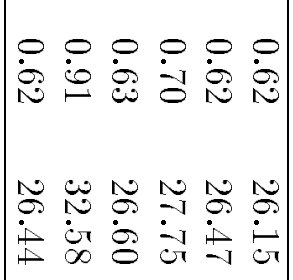 & 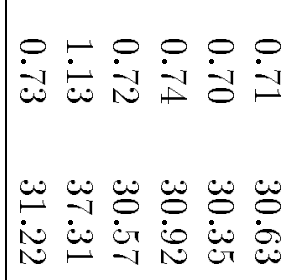 & 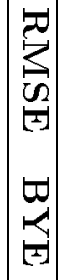 & 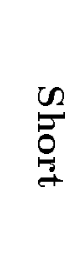 \\
\hline 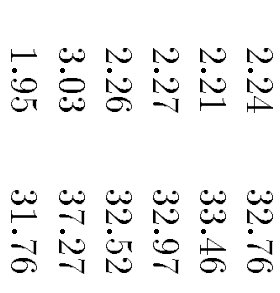 & 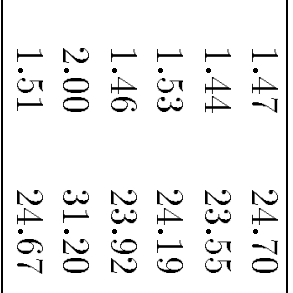 & 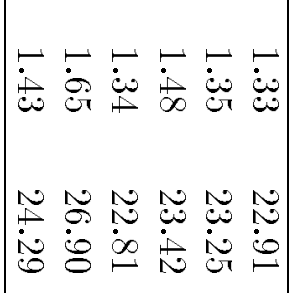 & 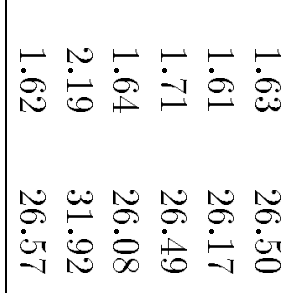 & 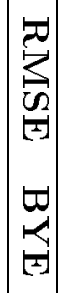 & 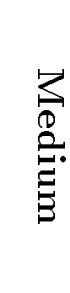 \\
\hline 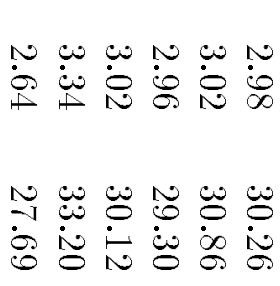 & 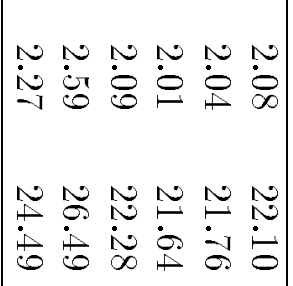 & 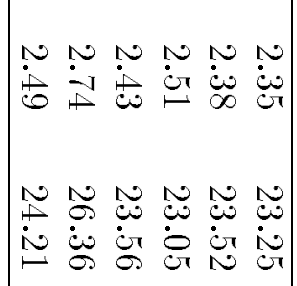 & 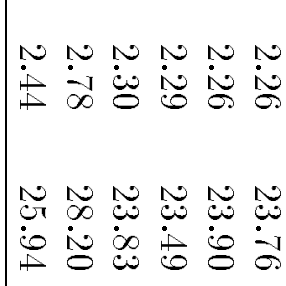 & 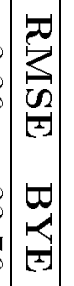 & $\stackrel{\circ}{\circ}$ \\
\hline 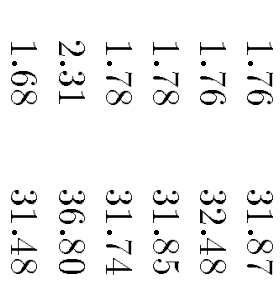 & 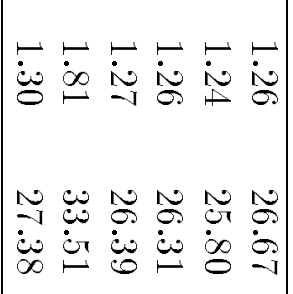 & 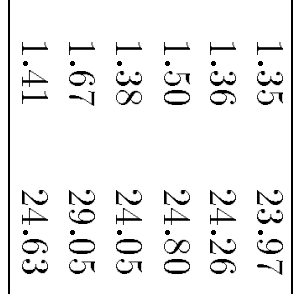 & 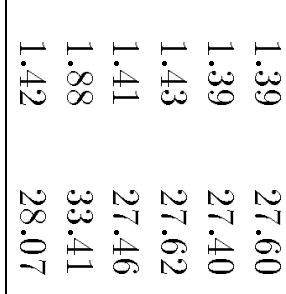 & 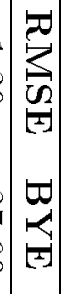 & \\
\hline
\end{tabular}

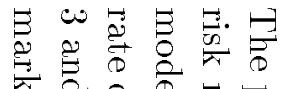

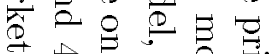
己ै. 고 T 00 o \& स्र

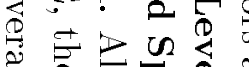

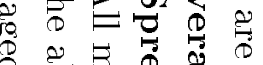
- 3 \%

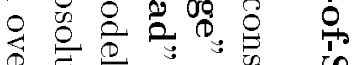

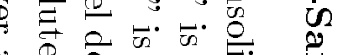

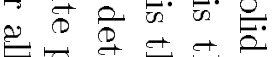

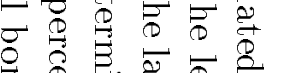

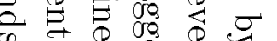
प0

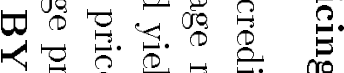
픙.

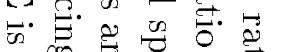

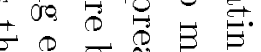

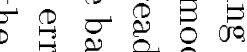

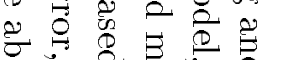
ज. 0 o

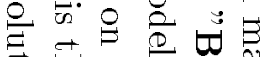

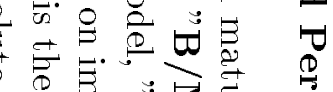

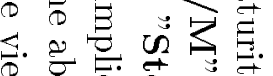

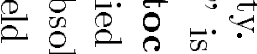

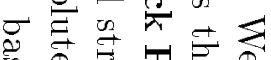

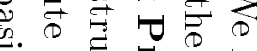

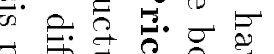

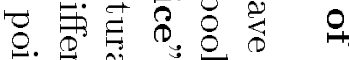

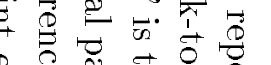

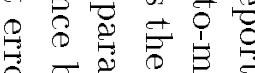

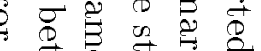
త $\vec{D} D \vec{D}+\vec{D}$

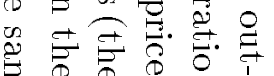

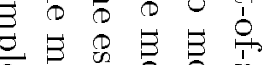

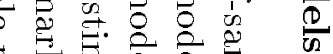
BD $\bar{D}$

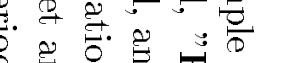
.

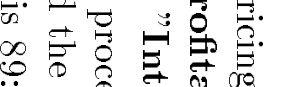

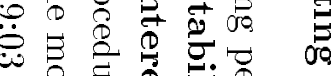

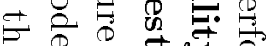
$\Rightarrow+\frac{1}{0} \cdot \vec{c}$ 焉. $\infty$ D $0 . \overrightarrow{0}$

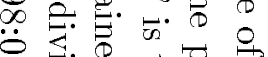

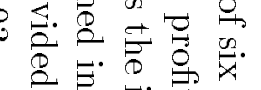

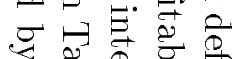
过

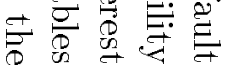




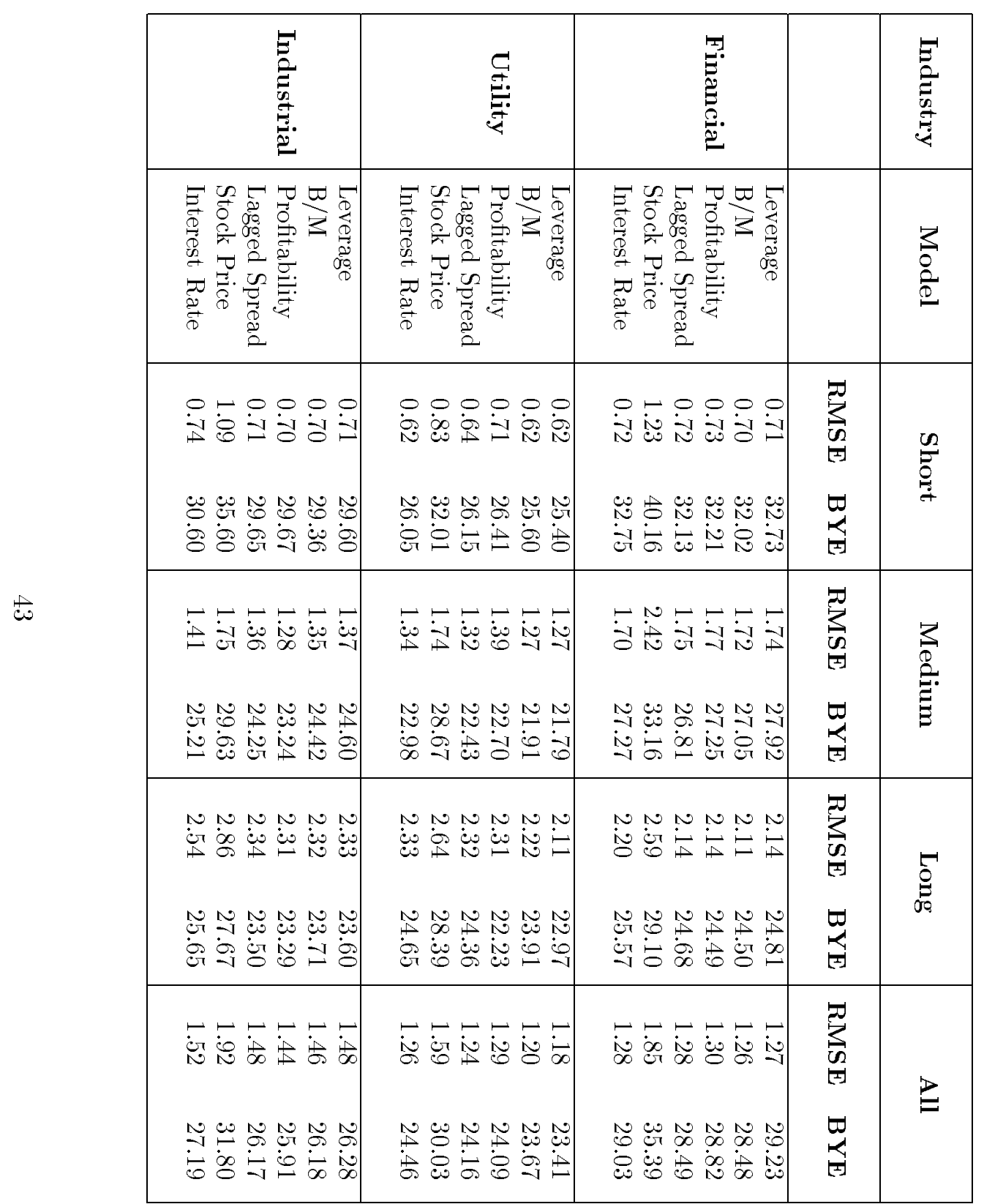

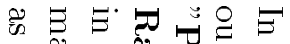

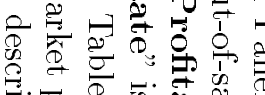

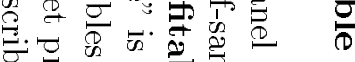

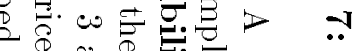

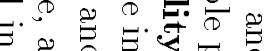

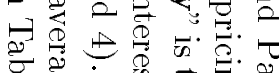

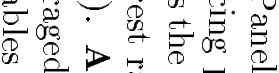

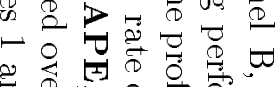

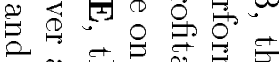

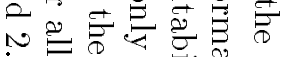

$\exists$ Эতّ

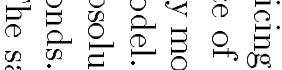

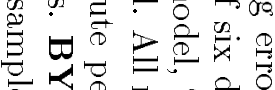

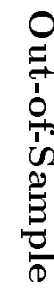

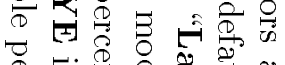

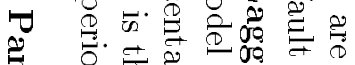

ठำ

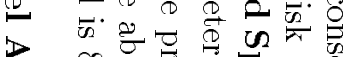

$\infty$ क.

ت.

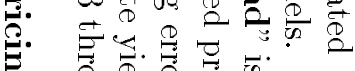

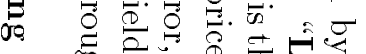

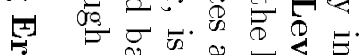

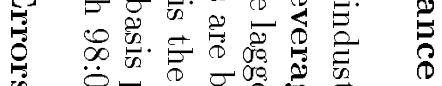

$\checkmark \quad 0$. D

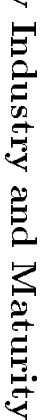

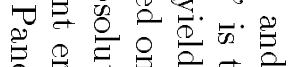

$\widetilde{8}$

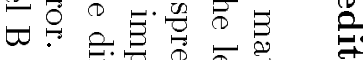

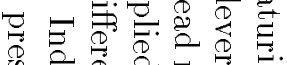

D

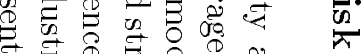

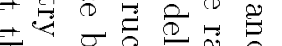

वे

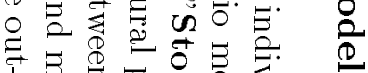

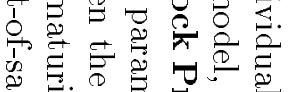

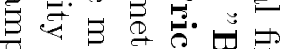

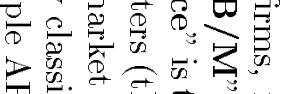

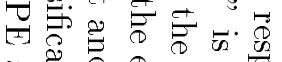

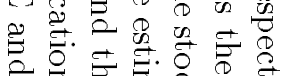

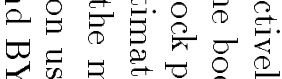

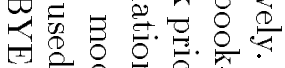

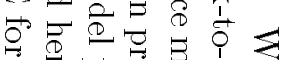

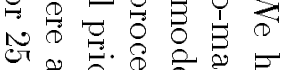

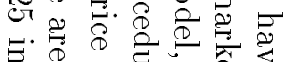

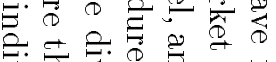

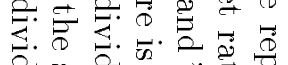

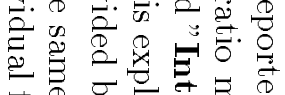

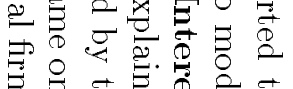

ינ: 


\begin{tabular}{|c|c|c|}
\hline 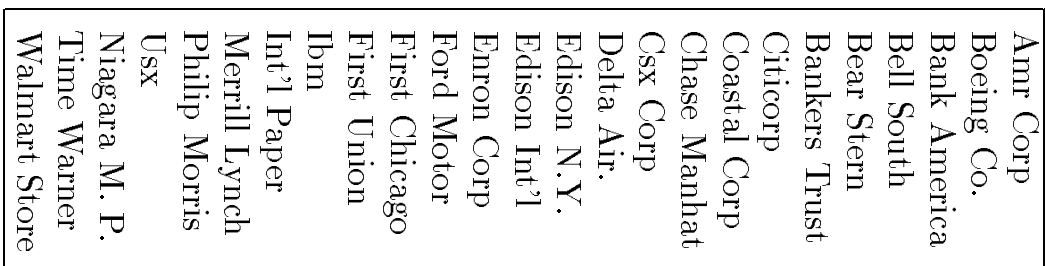 & & \\
\hline 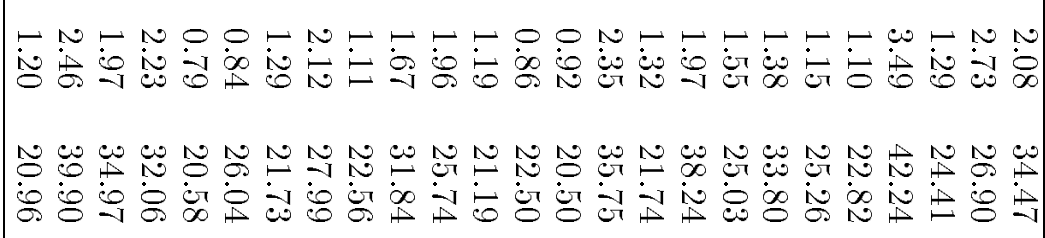 & 矛 & $\begin{array}{c}-1 \\
0 \\
0 \\
0 \\
0 \\
0 \\
0 \\
0\end{array}$ \\
\hline 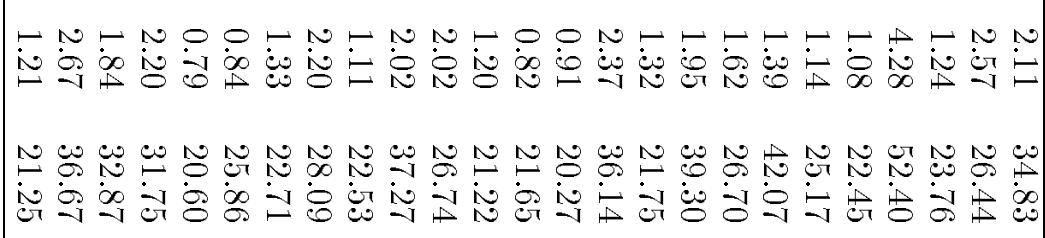 & 矛 & 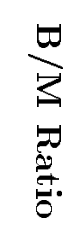 \\
\hline 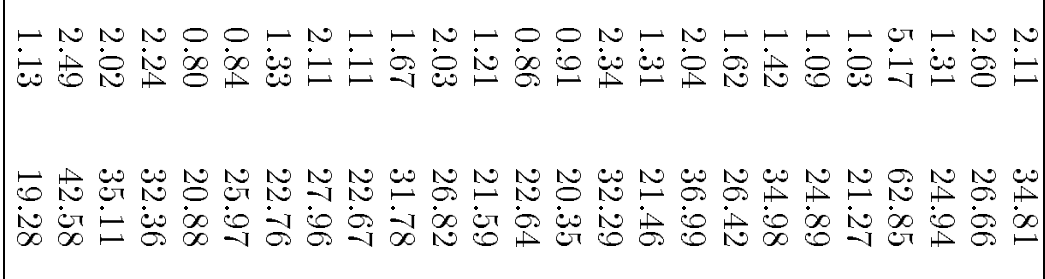 & $\underset{\forall}{\Delta}$ & 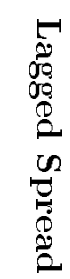 \\
\hline 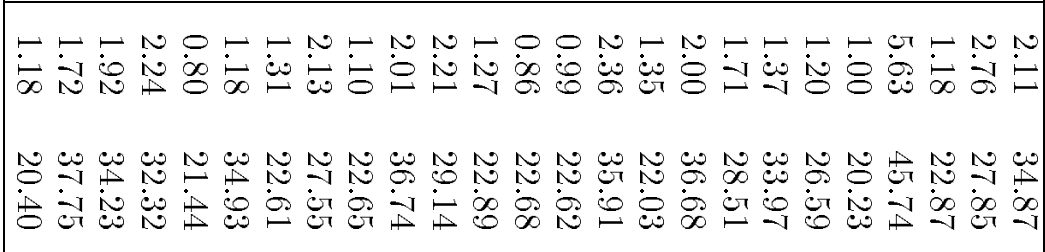 & 式 & 式 \\
\hline 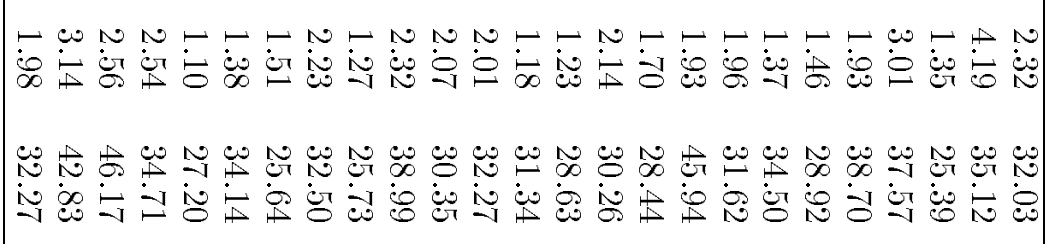 & 矛 & $\frac{0}{0}$ \\
\hline 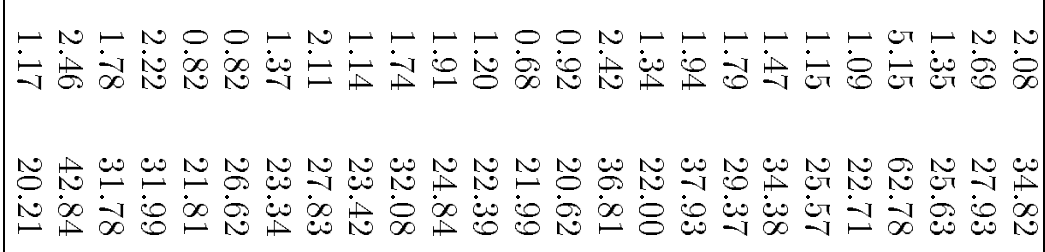 & $\underset{|r|}{\Delta}$ & 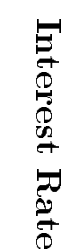 \\
\hline
\end{tabular}




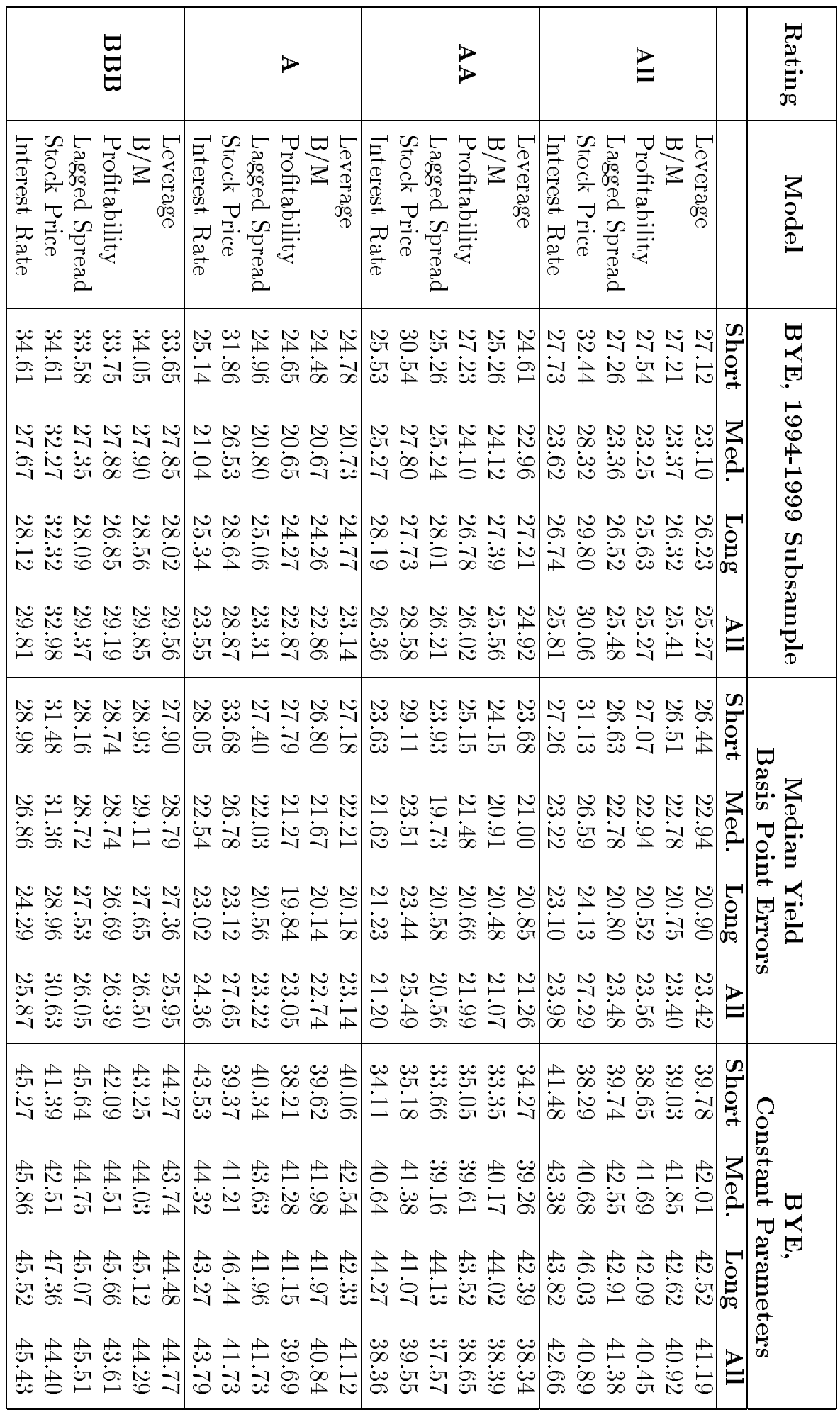




\begin{tabular}{|c|c|c|c|c|c|}
\hline لِّ & $D$ & $D_{D}^{D}$ & 当 & & 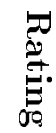 \\
\hline 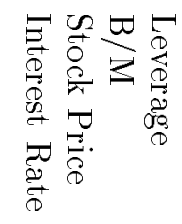 & 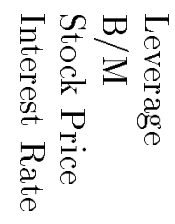 & 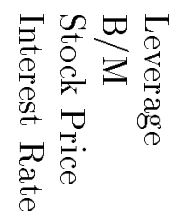 & 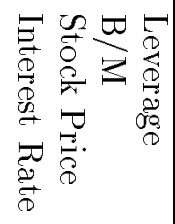 & & $\begin{array}{l}3 \\
0 \\
0 \\
0\end{array}$ \\
\hline $\begin{array}{l}\dot{0} \dot{0} \dot{0} \dot{0} \\
\dot{0}\end{array}$ & 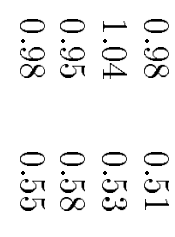 & 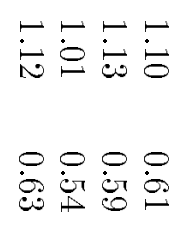 & 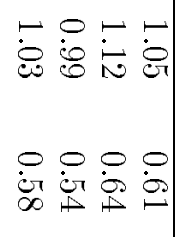 & 皿 & $\stackrel{\mathscr{L}}{2}$ \\
\hline 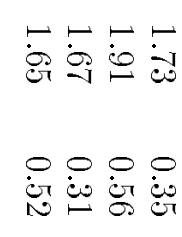 & 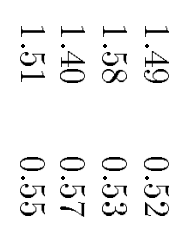 & 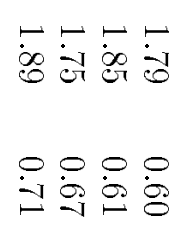 & 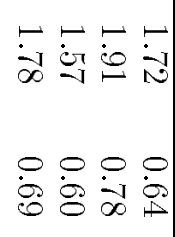 & 空 & 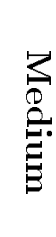 \\
\hline 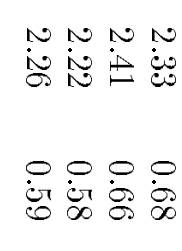 & 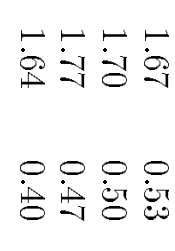 & 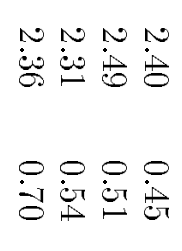 & 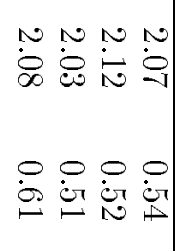 & 空 & $\overbrace{0}^{-1}$ \\
\hline 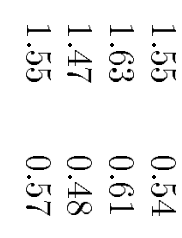 & 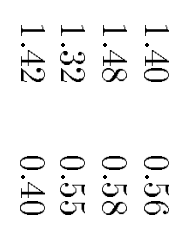 & 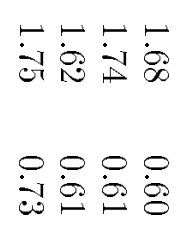 & 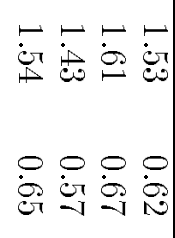 & 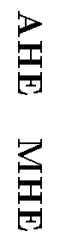 & $\stackrel{\Perp}{=}$ \\
\hline
\end{tabular}

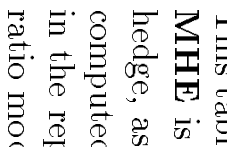

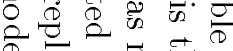

ใ.

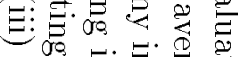

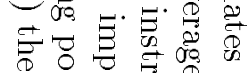

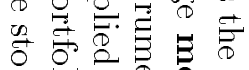

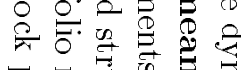

च.

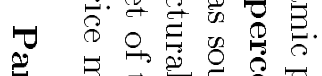

ब

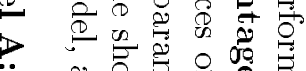

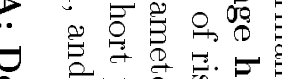

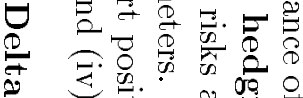

1 过

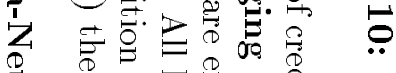

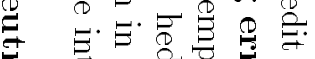

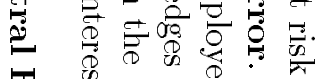

年

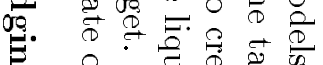

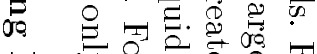

$\overrightarrow{0}$
$\frac{0}{0}$
$\stackrel{0}{\circ}$

펀

贾

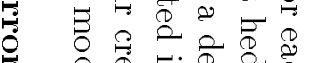

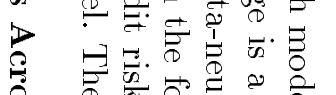

$\stackrel{2}{\Rightarrow}$

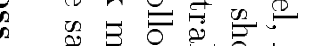

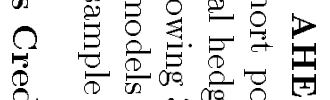

:

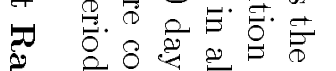

苟.

星

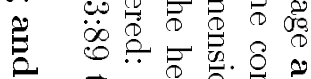

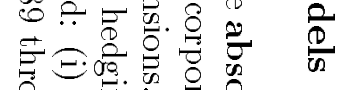

永

‥

过

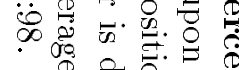

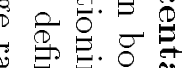

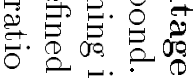

उ

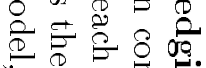

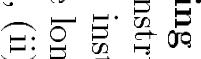

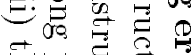

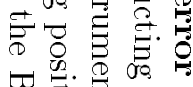

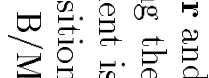




\begin{tabular}{|c|c|c|}
\hline 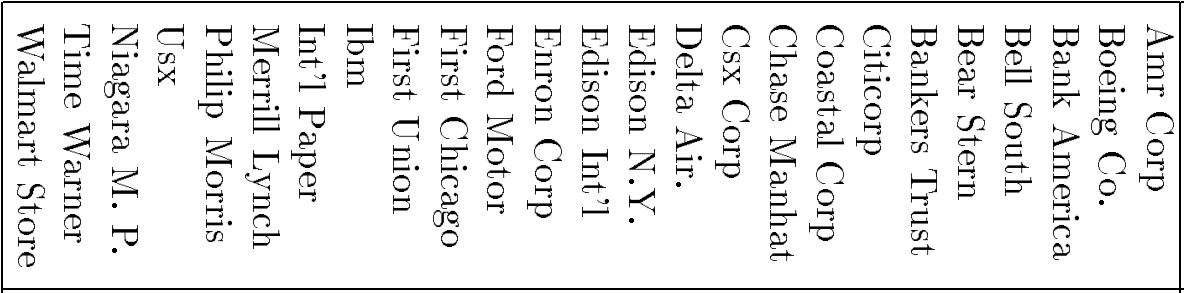 & & \\
\hline 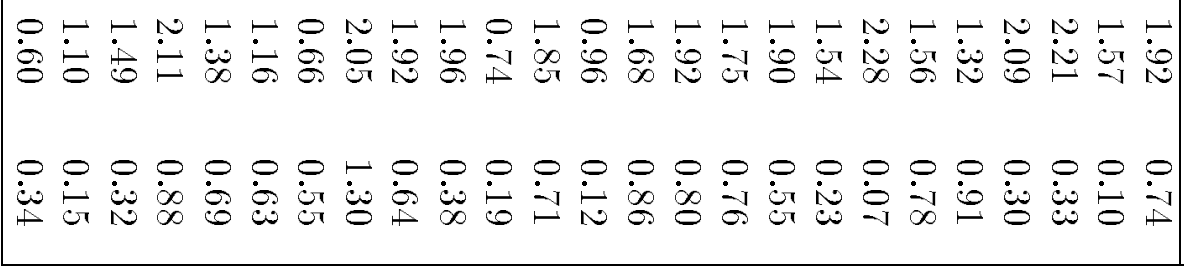 & 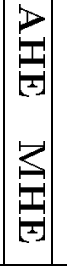 & 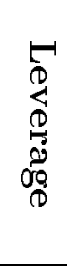 \\
\hline 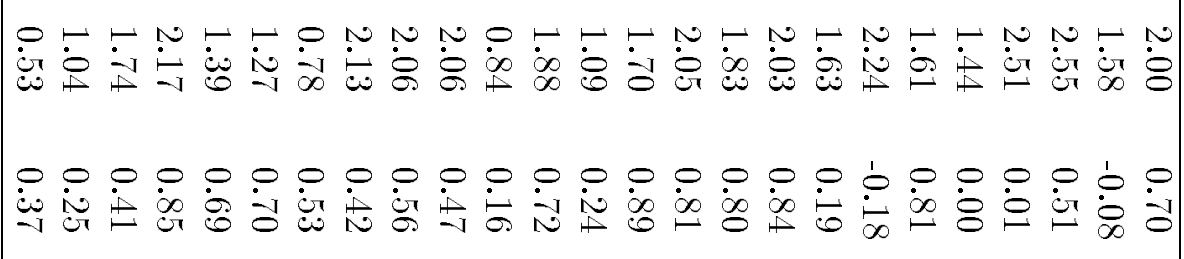 & $\mid$ & 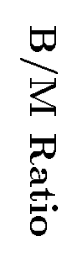 \\
\hline 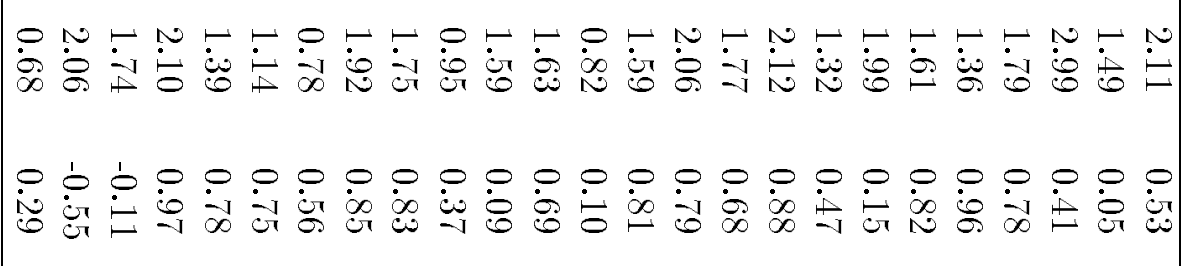 & 焉 & 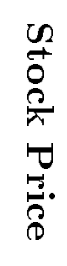 \\
\hline 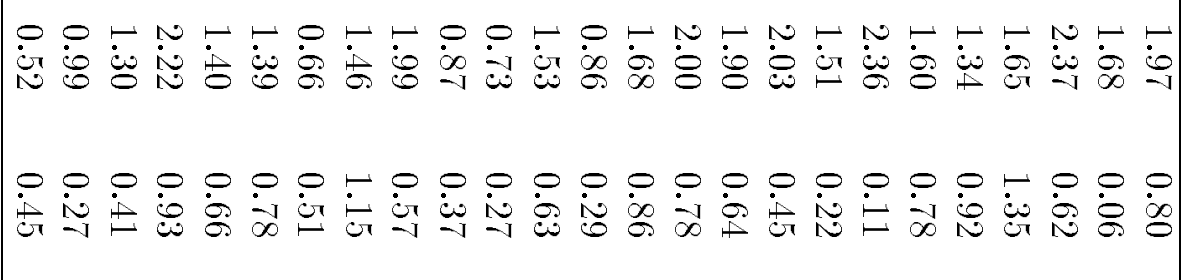 & 疍 & 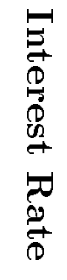 \\
\hline
\end{tabular}



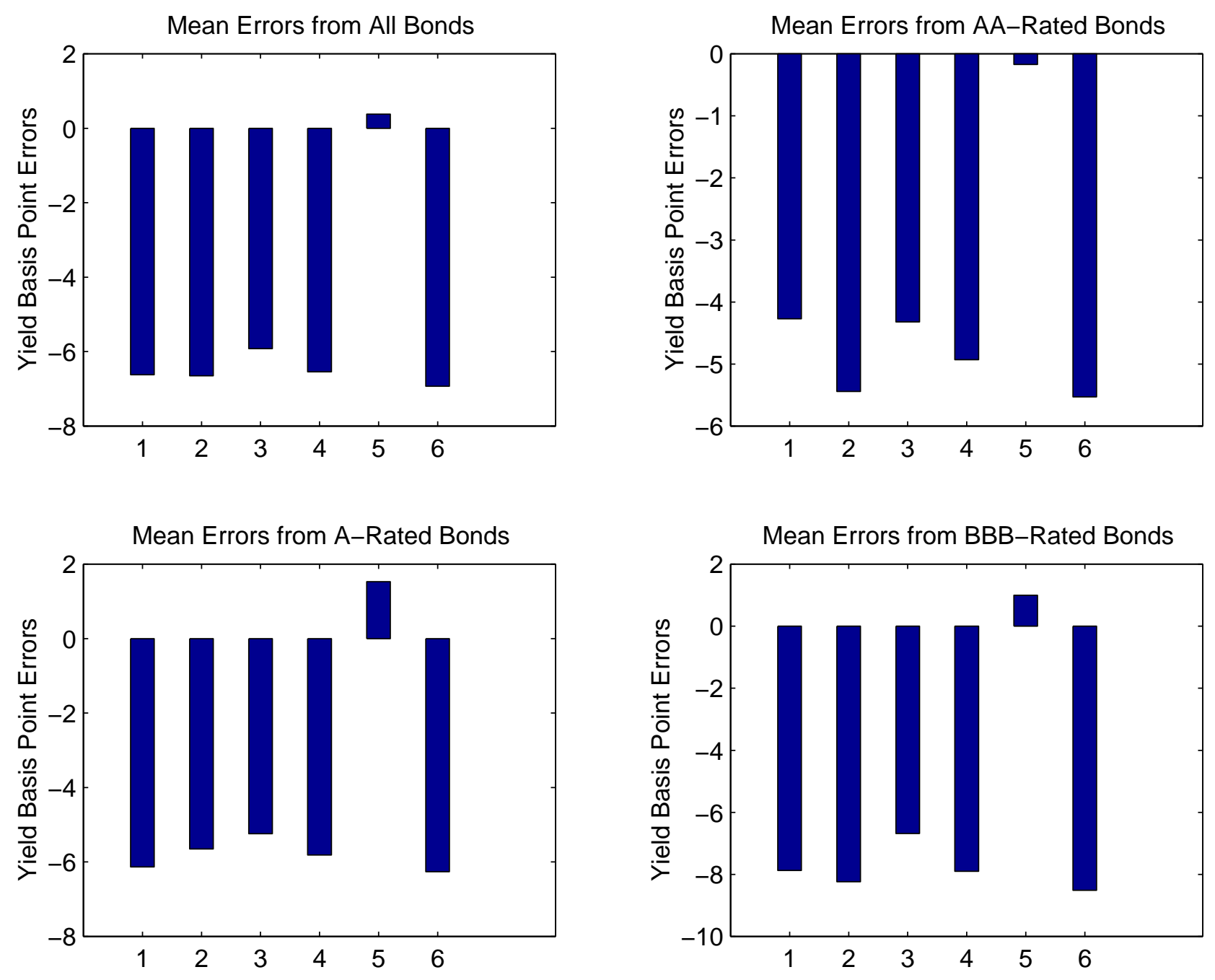

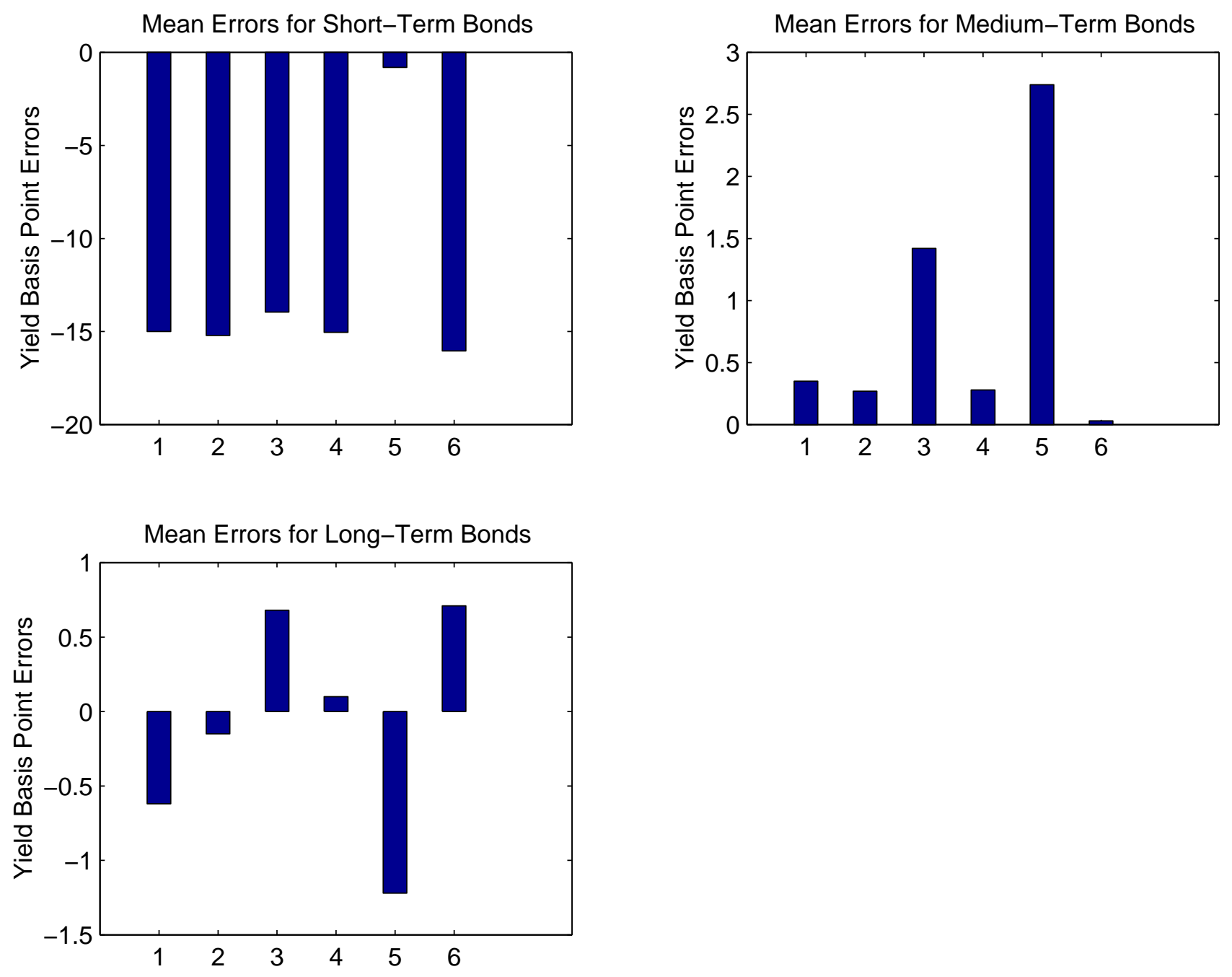
Figure 1: Out-of-Sample Mean Errors by Credit Rating (in Basis Points)

This graph displays the out-of-sample mean yield basis point errors for credit risk models. Model $\mathbf{1}$ is the leverage ratio model; Model $\mathbf{2}$ is the B/M ratio model; Model $\mathbf{3}$ is the profitability model; Model $\mathbf{4}$ is the lagged yield spread model; Model $\mathbf{5}$ is the stock price model; and Model 6 is the interest only model. The mean yield basis point error is the discrepancy between the market yield and the model determined yield. Yields are inverted by solving the following equation: $P(t, \tau)=\int_{t}^{t+\tau} c \exp [-Y(t, \tau) u] d u+F \exp [-Y(t, \tau) \tau]$, where $Y(t, \tau)$ is the yield-to-maturity and $P(t, \tau)$ is either the market or model-determined coupon bond prices. The results are shown by credit rating.

\section{Figure 2: Out-of-Sample Mean Errors by Maturity (in Basis Points)}

This graph displays the out-of-sample mean yield basis point errors for credit risk models. Model $\mathbf{1}$ is the leverage ratio model; Model $\mathbf{2}$ is the B/M ratio model; Model $\mathbf{3}$ is the profitability model; Model $\mathbf{4}$ is the lagged yield spread model; Model $\mathbf{5}$ is the stock price model; and Model 6 is the interest only model. The mean yield basis point error is the discrepancy between the market yield and the model determined yield. Yields are inverted by solving the following equation: $P(t, \tau)=\int_{t}^{t+\tau} c \exp [-Y(t, \tau) u] d u+F \exp [-Y(t, \tau) \tau]$, where $Y(t, \tau)$ is the yield-to-maturity and $P(t, \tau)$ is either the market or model-determined coupon bond prices. The results are shown by bond maturity. 